\title{
POBLAMIENTO PRÉHISTORICO Y COLONIAL DE MISIONES
}

\author{
Ruth Poujade*
}

\section{INTRODUCCIÓN:}

Los datos manejados en esta comunicación, están condicionados por las pocas investigaciones arqueológicas realizadas en la Provincia, donde vastos espacios geográficos permanecen en la oscuridad, tal es el caso de las zonas NE y Central, para las que hay precarios e imprecisos informes acerca de Sitios acerámicos y SE de Misiones, donde con excepción del trabajo de SEMPE en varios Sitios Guaraníes ubicados en los Dptos Oberá, San Javier y 25 de Mayo (inédito), y otros de RISSO citados por GIESSO, a los que no tuvimos acceso, y de la Primera Prospección (inédita) realizada por CALANDRA y DOGERTHY sobre la margen derecha del Río Uruguay en el área afectada por la Presa Garabí (NE de Corrientes y SE de Misiones: Dptos. Apóstoles, Concepción, San Javier y Oberá), no hay noticias de otros estudios, por una parte.

Y por otra, por los tipos de investigaciones puestas en marcha, las que respondían a diferentes objetivos y están encaradas con distintas metodologías, si bien no pudimos concretar correlaciones que permitieran una vinculación real con las fases establecidas en Brasil para las Tradiciones Culturales comunes a Brasil, Paraguay y Argentina, tratamos de establecer aproximativamente los procesos socio culturales del pasado.

Estudos Ibero-Americanos. PUCRS, v. XVIII, n. 1, p. 29-69, julho, 1992 
Utilizamos la tipología de sitios de ROVIRA (1989): "Sitios indígenas, Sitios de Frontera (Reducciones), y sitios europeos (Asentamientos europeos coloniales y posteriores)".

Como nos ocupamos del poblamiento precolombiano y colonial, y los sitios Europeos detectados y trabajados en Misiones, corresponden a los Siglos XIX y XX, nos referiremos exclusivamente a Sitios Indígenas y de Frontera.

En Misiones durante los últimos diez años han trabajado en campo, siguiendo un ordenamiento relativamente cronológico:

- Aisladamente en Sitios Indígenas: WACHNITZ, RISSO, LAGUZZI, GIESSO, SEMPE.

- Aisladamente en Sitios de Frontera: RISSO, GIESSO, y ROVIRA.

- Extensivamente (arqueología de Rescate) POUJADE, GIESSO, CALANDRA y DOGERTHY.

La inexistencia de estudios paleo-ambientales, y dado que los procesos socioculturales iniciados provablemente en el transcurso del Holoceno temprano, perduram en moméntos de la conquista y colonización hispana, nos llevaron a iniciar nuestra comunicación con una sistética descripción del ambiente actual, a fin de estabelecer relaciones hombre-habitat.

Puesto que la bibliografia da información sobre el problamiento pre-colombiano de Eldorado y Montecarlo, nos referiremos brevemente al mismo, tratando puntualmente la ocupación precolombina y colonial del NW y SW de Ms., cuyo conocimiento parcial a partir de la Arqueología es la resultante de los salvatajes vinculados a las Presas Urugua-í y Yacyretá (el últimino en marcha); y a las conclusiones de la Investigación inédita de ROVIRA en MCM1 (Misiones Dpto. y Municipio Candelaria, Misión Sitio 1) por tratarse de un aporte prácticamente desconocido de gran valor para la Arqueología Histórica del Area Platina.

\section{UBICACIÓN POLÍTICA, SUPERFICIE Y MEDIO AMBIENTE:}

La Provincia de Ms. ocupa el extremo Nordeste de la República Argentina, limita al N. S. y E. con la República Federativa del Brasil y al W con la República del Paraguay y con la Provincia de Corrientes (carta 1), sus puntos extremos son:

N. En la ribera del Iguazú-Lat. $25^{\circ} 23^{\prime}$ S; Long. $54^{\circ} 07^{\prime} \mathrm{W}$.

S. En la ribera del R. Uruguay, al S. de la localidad de Barra Concepción, Lat. $28^{\circ} 09^{\prime}$ S; Long. $55^{\circ} 35^{\prime} \mathrm{W}$. 
E. AI NE de la localidad de Bernardo de Irigoyen entre las nacientes de los ríos Pepirí Guazú y San Antonio. Lat. 26² $15^{\prime}$ S; $53^{\circ} 38^{\prime}$ W.

W. En la ribera del arroyo del arroyo Itaembé Lat. $27^{\circ} 26^{\prime}$ S. Long. $56^{\circ} 04 \mathrm{~W}$.

Su superficie es de $29.801 \mathrm{~km} 2$ y representa el $0,8 \%$ del total nacional y el $1,1 \%$ del total continental.

Se subdivide en 17 Departamentos (carta 2).

Se trata de una zona geográfica heterogênea que guarda mayores semejanzas con los territorios brasileño y paraguayo colindantes que con el resto del país.

El subsuelo comienza con la formación del macizo de Brasilia, que sirve de sustrato básico sobre el cual se asientan basaltos, areniscas, metasedimentarias y lateritas (carta 3).

Los basaltos se desarrollan fundamentalmente a ambos costados del eje longitudinal de la Provincia. Las lateritas tienen su difución mayor entres sectores: el borde del Alto Paraná, el dorso de la sierra central y la llanura del SW, las areniscas se presentan en canteras cercanas al R. Paraná fundamentalmente en el SW de la Provincia. Y las meta-sedimentarias en el sector S. SE y SW.

Todo el subsuelo fue afectado por diversos movimientos y fallas; de éstas, las de mayor envergadura pertenecen a los cursos de los ríos Paraná y Uruguay.

Los movimientos de ascenso en masa de los basaltos activaron la erosión de los ríos locales, dando como resultado los profundos valles fluviales que se pueden observar sobre todo en los sectores Central y NE de la Provincia.

Las lateritas contribuyen a formar el suelo rojoy arcilloso característico de Ms., Paraguay y S. de Brasil.

El relieve de Misiones (carta 4), generalmente es definido como de tipo amesetado, pero resulta más realista identificarlo como um sistema serrano dorsal muy erosionado, que va descendiendo desde el borde oriental hacia el SW, desde 800 m.s.n.m. en Berhardo de Irigoyen hasta menos de 100 m.s.n.m. en Apóstoles, con pendientes más abruptas hacia el E que hacia el W (o sea hacia el Uruguay y el Paraná respectivamente).

Contratando con este relieve quebrado, una considerable extensión de la Provincia se halla cubierta por una llanura ondulada, atravesada por valles fluviales anchos. Ocasionalmente aparecen elevaciones relativas que se destacan en el paisaje, y reciben el nombre de "capones" o "cerrittos", en general, cubiertos por una vegetación diferente de árboles pequeños, que los hace más visibles.

Las zonas llanas o con escasa pendiente presentan la forma de una Y, cuya base se encuentra en el SW; el brazo más corto no acompaña todo el Alto Uruguay que en su curso superior está circundado por un relieve muy quebrado y el más largo 
sigue la dirección de la costa del Alto Paraná, donde se suceden una serie de lomadas largas, con correspondientes depresiones en las que corren gran cantidad de ríos y arroyos, con valles fluviales que tienden a ensancharse al desembocar en el Paraná, con lo cual el relieve se hace menos abrupto.

Una topografía semejante acompaña al R. Iguazú.

Por lo tanto el área serrana queda reducida en su mayoría al centro de la Provincia y su conformación se asemeja a una columna vertebral.

Transversalmente a ella, las Sierras menores marcan los interfluvios. Este sistema serrano penetra en Brasil y su altura asciende continuamente hacia el E.

El tipo de clima que corresponde a Ms. es el Subtropical sin estación seca, habitualmente sin variaciones notables dentro del territorio, salvo un descenso de temperatura de SW e NE y aumento en las precipitaciones de W a E.

Las heladas son regulares y aparentemente se dan en todo el territorio provincial. Las precipitaciones nivales son relativamente comunes, pero no frecuentes, afectando las zonas más elevadas N-NE y eventualmente el S.S.E. (carta 5).

A lo largo del año la temperatura sufre variaciones muy notables, siendo la amplitud térmica anual de $11^{\circ} \mathrm{y}$ desplazándose las temperaturas medias entre $15^{\circ} \mathrm{y}$ $26^{\circ}$. Sin embargo, se dan alteraciones importantes en situaciones especiales como lo indican registros de casi $7^{\circ}$ bajo cero o máximas de más de $41^{\circ}$.

Los días con heladas son raros, sobre todo en áreas cercanas a los grandes ríos ( 1,7 heladas por año en Posadas y 3,1 en Iguazú) pero aumentan gradualmente hacia el interior de la Provincia ( 9,1 en Loreto) y son mayores en zonas altas.

Las precipitaciones están ligadas al anticiclón del Atlântico Sur y por lo tanto se incrementan hacia el NE.

Sobre el Alto Paraná las lluvias son abundantes, no descienden de $1051500 \mathrm{~mm}$. anuales disminuyendo hacia el SW y aumentando hacia el borde oriental donde el quebrado relieve define pequeñas áreas de microclimas; registros esporádicos o indirectos llegan a assignar $2000 \mathrm{~mm}$. anuales en algunas localidades del Alto Uruguay.

No hay una estación verdaderamente "Seca". Los períodos de menor precipitación son julio y agosto, y en menor medida noviembre y diciembre.

La información obtenida está referida a promedios, por lo tanto ocasionalmente hay períodos de sequía que son más evidentes en el SW.

Los vientos predominantes son los delE. SE y NE y menor medida S y N, siendo notable la poca incidencia del sector occidental.

El Sistema hidrográfico presenta una extrema densidad que os consecuencia directa del tipo de clima y del relieve. (carta 6). 
En la periferia fluvial de Misiones desembocan aproximadamente 800 cursos permanentes de agua de muy diversa categoría, desde pequeños arroyuelos o grandes ríos.

Debido al relieve local se forman dos líneas divisorias de aguas que confluyen en el punto más alto de la Provincia, ubicado al NE (B. de Irigoyen), que aparece como el sector a partir del cual se desarrollan las cuencas principales: las del Paraná, Uruguay y la del Iguazú (Subcuenca del Paraná).

El Alto Paraná, río de régimen alóctono, penetra en Misiones por el ángulo $\mathrm{NW}$, poseyendo la cuenca de mayor desarrollo. Si bien tiene crecidas oscilantes por lo general alcanza sus máximos niveles entre fines de verano y pricipios de otoño. El caudal medio en Puerto Posadas es de 11.000 m3/seg.; el mínimo 3.200 m3/seg..

El cauce se ensancha de $\mathrm{N}$ a S., se inicia con $300 \mathrm{~m}$. en la desembocadura del R. Iguazú y llega a $2.500 \mathrm{~m}$. en la altura de Posadas.

El río Iguazú recorre un trecho relativamente corto desde que ingresa a territorio argentino y hasta su desembocadura en el Paraná. Es un río de régimen subtropical (tal como lo son los afluentes locales), alimentado por precipitaciones distribufdas a lo largo de todo el año, con solo 2 períodos de crecientes notables en otońo y primavera provocadas por grandes lluvias. El cauce del Iguazú es ancho hasta el lugar donde el río corta la Sierra de la Victoria y produce las Cataratas del Iguazú. A partir de allí el cauce se encajona hasta desembocar en el Paraná, con caudal medio de 1.466 $\mathrm{m} 3 / \mathrm{seg}$..

La tercera cuenca (segunda en superficie) es la de Uruguay. También se comporta según un régimen subtropical con dos crecidas anuales.

Su caudal básico promedio es de $2.260 \mathrm{~m} 3 / \mathrm{seg}$., presenta además una cantidad de accidentes motivados por las características topográficas del lecho, siendo los más usuales los rápidos o "correderas" que dificultan enormemente la navegación. Al llegar a la Argentina, se precipita por un salto muy particular, debido a que el corte se halla en forma longitudinal al cauce, lo cual origina una cascada de $3 \mathrm{~km}$ de longitud (Salto Moconá). Posee un cauce estrecho en su primer tramo argentino que va ensanchando hacia el S., recibe en Misiones gran cantidad de afluentes.

El régimen de los ríos locales depende fundamentalmente de las precipitaciones que suceden dentro de la Provincia y puesto que los ríos son cortos, se notan importantes diferencias diarias. Las grandes crecidas son frecuentes y la consecuencia mayor se evidencia en el curso inferior, con valles más bajos y anchos.

La gran riqueza hidrográfica de Misiones ha hecho que la Provincia sea el marco de un conjunto de proyectos de aprovechamientos hidroeléctricos provinciales, de los cuales el de mayor envergadura Urugua-í fue acompañado de Rescate Arqueo- 
lógico; nacionales y binacionales: Yacyretá en ejecusión con Rescate Arqueológico en marcha; $y$ en proyecto Garabí y Corpus, el primero Brasil-Argentina y el segundo Paraguay-Argentina, en ambos casos, aparentemente está contemplado el salvataje Arqueológico.

Desde el punto de vista fitogeográfico, siguiendo a MARTINES CROVETTO, la Provincia de Misiones está incluída en la Provincia Paranaense o subtropical Oriental, que comprende desde el extremoS. de Brasil y W. de la Serra do Mar, hasta el Centro de Río Grande do Sul, extremo Nordeste de Argentina y E de Paraguay.

La vegetación es la selva subtropical o selvas hidrófilas con predominio de Laureaceas; apareciendo bosques con araucarias sobre el planalto y sabanas serranas, pero también en las zonas más bajas hay una clara dominancia de Sabanas. Esta Provincia está formada por los siguientes distritos: el de la selva mixta, el de los Pinares, el de los campos y el serrano (ausente en Misiones).

El distrito de selva mixta: o sector misionero, ocupa casi toda la Provincia de Misiones (carta 7).

Presenta una vegatación de selva compacta, dentro de la cual se pueden diferenciar los siguientes estratos: uno arborreo que se conserva en pequeñas superficies como ser Parques y Reservas o bien en zonas de dificil acceso; el Sotobosque compuesto por numerosas especies de árboles pequeños y arbustos altos y bajos; uno de bambúceas y en sitios con suelos profundos y algo húmedos facies de helechos arborescentes, un estrato herbáceo y uno nouscinal.

En esta selva se encuentran casi todos los tipos biológicos vegetales, predominando las megafanerófitas de hojas perenes, y algunos tipos biológicos especiales como plantas mimecofilas.

Este Distrito presenta comunidades vegetales características que permiten a MARTINEZ CROVETTO subdividirlo en: Distrito de: los Laureles, del Urunday, del Palo Rosa, de los helechos arborescentes y Fluvial. (carta 7).

El Distrito de los Pinares S/ Cabrera o Sector Planalto según MARTINEZ CROVETTO ocupa la zona elevada del S de Brasil llamada: Planalto austro-brasileño y el NE de Ms. (carta 7).

Se caracteriza por la presencia de araucaria angustifolia (pino Paraná), que interviene en la constitución de diversas asociaciones que en conjunto fueron denominadas Formación de Araucarias.

El distrito de los campos se extiende por el S de la Provincia de Misiones y NE de Corrientes penetrando en R. Grande do Sul, Santa Catarina y Paraná, y zonas vecinas de Paraguay (carta 7). Son terrenos sinmontes, cubiertos por comunidades de pajonales semi-natureles de los "campos". 
Las comunidades vegetales que ocupan este distrito son de carácter edáfico y se deben a la existencia de un manto de meláfiro a poca profundidad que actúa como aislante, entre horizontes superiores y las napas freáticas, predominan las comunidades herbáceas ricas en especies, y aisladamente aparecen cerritos de escasa altura "capones" cubiertos por árboles pequeños.

En la Provincia se identificaron 9 grupos de suelos; los seis primeros derivados de basaltos, el 7 de areniscas, y los 8 y 9 provienen de terrazas fluviales. (carta 8).

- El Grupo 1 se desarrolla en el sector S.S.W. de la Provincia (alrededores de Bonpland y Candelaria); se trata de suelos poco profundos de drenaje difícil por la poca pendiente y absorción de agua, con escasa utilidad para la agricultura por su precaria fertilidad. Hoy utilizado para cría de ganado.

- El grupo 2 se ubica en áreas ondulasa, por lo general rodeando a la base del sistema serrano y en los valles fluviales; son suelos profundos bien drenados, muy fértiles, de coloración marrón oscura, muy aptos para cultivos anuales.

- El Grupo 3 es similar al 2, se desarrolla sobre relieves más quebrados, siendo más común hacia el N.E.

- El Grupo 4, restringido casi exclusivamente a Cerro Azul (zona S.S.W.), son suclos hallados en relieves heterogéneos y bien drenados, de un color rojo oscuro, fértiles y muy erosionados, sobre todo después de períodos de sequía.

- El Grupo 5 es el más característico de Ms., el típico suelo rojo, sobre al cual se dió la mayor parte del sistema de colonización e implantación de cultivos anuales. Se desarrolla en tres sectores principales: SW, dorso de la sierra y costa del Paraná, es decir sobre terrenos de leve ondulación o planos.

Son muy erosionables y de fertilidad superficial.

- El Grupo 6, restringido a Bernardo de Irigoyen (NE), abarca suelos de poca pendiente, profundos, con buen drenaje y muy fértiles, de coloración marrón rojiza.

- El Grupo 7, derivado de areniscas, es reconocible en las zonas costeras del Paraná, sobre todo cerca de San Ignacio (S.W). Son suelos arenosos profundos y bien drenados, de uso potencial muy limitado.

- El Grupo 8 se ubica sobre terrazas fluviales de formación reciente ya sea por erosión o por depósito de sedimentos. Corresponde a suelos negros, profundos pero poco fértiles, que se ubican en la base de los valles fluviales, tanto de los afluentes del Paraná como del Uruguay.

- El Grupo 9, desarrollado sobre relieves planos, de terrazas fluviales antiguas, puede localizarse sobre todo en el Alto Paraná entre Candelaria y Posadas (S.S.W): abarca suelos rojizos de buen drenaje pero de fertilidad y yso limitados. Tanto los de este Grupo como los del anterior son aptos para cultivos de arroz. *FAUNA. 


\section{POBLAMIENTO PRE-COLOMBIANO (SITIOS INDÍGENS)}

Misiones forma parte de la Región Cultural Tierras Altas Orientales definida por GIESSO y POUJADE en 1986, integrada por los estados de Paraná Santa Catarina, y Río Grande do Sul (exeptuando la franja Litoral Atlântica) $\mathrm{N}$ de la Provincia de Corrientes y Misiones en Argentina y Paraguay.

Como ya dijeramos las escasas investigaciones arqueológicas encaradas en la Provincia, la inexistencia de estudios paleo-ambientales y de dataciones por $\mathrm{C} 14$ solo permiten establecer secuencias cronológico-culturales relativas y de caráter tentativo.

Por lo consignado, utilizaremos el esquena cultura de MENGHIN, reformulado por RISSO, corrigiendo fechas vinculadas a Eldoradense e incorporando la tradición Umbú que fechamos por aproximación con los datos proporcionados por las investigaciones brasilñas.

Altoparanaense-Humaitá (MENGHIN) 8000 a 2000 aC.

Industria 3 de Mayo (RISSO) $-3000 \mathrm{aC}$.

Umbú (por inferencias de Brasil) 4000 aC. a 1500 dC.

Eldoradense-Taquara (por inferencias de Brasil) 120 a $1500 \mathrm{dC}$.

Tupiguaraní 1200 a $1500 \mathrm{dC}$.

Período hispano-indígena (siglos XVII a XVIII).

3.1. Cazadores-recolectores portadores de la Tradición Altoparanaense-Humaitá (carta 9).

Los vestigios más antiguos de la presencia humana en Ms. corresponden al Altoparanaense, que integra la tradición Humaitá, expresión de cazadores-recolectores de floresta subtropical.

Se trata de sitios a cielo descubierto: Campamentos y Talleres o Talleres-cantera o Talleres-Campamento, en los que no fue posible reconocer ningún vestigio de estructura habitacional, y los hallazgoz en su mayoría son superficiales.

Estas ocupaciones están situadas cercanas a las margenes de los ríos Paraná y Uruguay y a las de sus principales afluentes, dentro de la selva subtropical en zona Centro W, Mediterráneo-central y Centro E (WACHNITZ, RISSO, POUJADE) y entre 100 y 200 m.s.n.m. (carta 9).

La industria Altoparanaense está constituída por instrumentos sobre nucleo y sobre lascas espesas predominando los primeros, trabajados por percusión directa. 
Los instrumentos más representativos son: choppers, chopping-tools, bifaces rectas y curvas (clavas humerangides), picos, raederas alargadas, raspadores planoconvexos, etc.

Materia Prima: Basalto y rocas meta-sedimentarias.

La ubicación de los sitios, a lo largo de los valles de los ríos Paraná y Uruguay y principales afluentes, poblados por abundantes peces y en medio de la selva subtropical, optima en especies comestibles, alucinógenas y medicinales, rica en animales para caza, permite inferir el gran valor de la relación de los cazadores-recolectores sin puntas de proyectil líticas con los nichos ecológicos que les daban sustento y el sentido del nomadismo estacional.

MENGHIN (1957) establece cuatro etapas en el desarrollo del Altoparanaense, basadas en la tipología y en su relación con antiguas terrazas del R. Paraná.

Altoparanaense I, II, III, IV; con posterioridad WAGHMTZ (1984), luego de una excavación en el valle de Amoité, considera que las tres fases son en realidad tres industrias diferentes.

Con fines de información proporcionamos las denominaciones dadas por WASCHITZ, pero entendemos es menestrar realizar nuevas investigaciones para acceder a conclusiones definitivas.

Altoparanaense I - Amoiteense.

Altoparanaense II (Clasico) - Altoparanaense.

Altoparanaense III - Paty cuarense -

Altoparanaense IV - Rotelaense - associado a cerâmica provablemente de tradición Taquara.

Cabe destacar que en el marco de un Relevamiento Arqueológico de Ms. (POUJADE LAGUZZI 1979-1980 inédito) que abarcó las zonas Centro - W y Centro - mediterránea y SE de Ms. se detectaron sitios a cielo descubierto en los que sobre suelos lateríticos, aparecian superficialmente materiales pertenecientes a las cuatro Fases Altoparanaense mezclados con cerámica Tupíguaraní.

3.2. Cazadores-recolectores portadores de las Industrias de 3 de Mayo. RISSO 1980 (carta 9):

RISSO determina estas industrias en base a la excavación de una gruta ubicada en zona de selvas subtropicales, sobre la margen derecha del arroyo 3 de Mayo (afluente del R. Paraná), Dpto. Gral. San Martín, donde aisló dos niveles: uno precerámico y otro cerámico. 
El contexto de este sitio comprende: indicios líticos ( 2 industrias una sobre nucleo, trabajada por percusión directa, y otra sobre lasca trabajada tanto por percusión directa como indirecta, con núcleos preparados), materia prima preponderante: Basalto. Elementos óseos: agujas, puntas, anzuelos, numerosos huesos pulidos, etc. Indicios conchíferos: instrumentos y adornos sobre valvas de molusco. Tiestos lisos muy homogéneos. Restos malocológicos: gran cantidad de valvas en todos los niveles de excavación con selección de especies. Restos faunísticos, también con elección de especies. Fogones en los dos niveles, carbón, restos humanos en NII.

RISSO establece que N II 0,20 a $0,40 \mathrm{~m}$. representa una etapa de cazadoresrecolectores pre-cerámicos que ubica aproximadamente en el $3000 \mathrm{aC}$ y que N I $0-0,20 \mathrm{~m}$. expresa a cazadores-recolectores que conocían cerámica aparentemente Eldoradense-Taquara, y cronológicamente coloca N I en el 1500 o $2000 \mathrm{aC}$.

La autora relaciona c/u de los niveles con diferentes sitios trabajados en el S. de Brasil y la industria sobre lascas con el Fortalecense establecido por LAGUZZI y CORDEN (1962) en el arroyo Fortaleza Dpto. San Pedro (Misiones).

Entendemos es menester detectar y trabajar nuevos sitios, a fin de poder instaurar el área ocupada por los habitantes de la Gruta 3 de Mayo establecer sus estrategias económicas, sus modelos de asentamiento y determinar el momento en que adoptaron el uso de la cerámica que corresponde a la Tradición Taquara en la Región Tierras Altas Orientales.

GIESSO vincula N II con los sitios más antiguos trabajados en el Arroyo Urugua-í (Unidade a)(Informes inéditos del Rescate Arqueológico Urugua-í 1986 y 1988)

3.3. Cazadores-recolectores portadores de la Tradición Umbú (carta 9):

Esta tradición fue identificada por RISSO en 1969 en un sitio uticado en el Dpto. Eldorado, por GIESSO en 1986 (op. cit.), en 2 sitios del Dpto Iguazú (Unidad b), y por POUJADE en 1986 en 15 sitios del Dpto. Capital (Rescate Arq. Yacyretá, 1988).

Se trata de ocupaciones a cielo descubierto, talleres-cantera y talleres campamento en los que no se identificaron estructuras habitacionales, y los hallazgos en su mayoría son superficiales, aunque los tres investigadores lograron aislarlos estratigráficamente. 
El sitio del Dpto. Eldorado "Industria Ulf Monsted" está ubicado aproximadamente a $2 \mathrm{Km}$ del Arroyo Piray Miní (afluente del R. Paraná) en sedimentos aluviales, y la vegetación que lo rodea es de gramíneas tipo sabana (RISSO 1976).

Los dos sitios del Dpto. Iguazú, ubicados uno sobre la margen izquierda y otro sobre la derecha del arroyo Urugua-í, afluente del R. Paraná (Unidade b), están en suelos limo-arcillosos sin estratificación, muy próximos al curso de agua principal, frente a una corredera del río, a una altura de 2 a $7 \mathrm{~m}$. sobre el nivel del agua. Recursos litológicos: cantos rodados de tamaño mediano $(10$ a $15 \mathrm{~cm})$ de limonita of ftanita, en mucha menor proporción cuarzo basalto y cuarcita. La distribución del material es homogénea (no se observan concentraciones). Los hallazgos se ubican entre 70 y 80 $\mathrm{cm}$ de profundidad con alta densidad de materiales. (GIESSO op. cit.).

Los 15 sitios del Dpto. Capital, ubicados en zonas bañadas por el R. Paraná, están en sedimentos aluviales erosionados por el mismo río o en su lecho sobre el manto basáltico.

De ellos, 14 son talleres-cantera con gran densidad de materiales concentrados zonalmente sobre el manto basáltico, o incertos en albardones de 7 a $10 \mathrm{~m}$ de altura sobre el nivel del agua, en un suelo relativamente desarrollado (fuerte estructura columnar) de color grisáceo, a los $70 \mathrm{y}$ hasta los $100 \mathrm{~cm}$. de profundidad, al que se sobrepone un sedimento más moderno edafizado en otro lugar. Todos estos sitios están entre 74,5 y 89,0 m.s.m.n.

El décimo quinto sitio es un paradero taller que está en la porción más alta de la Is. Cañete 83 m.s.n.m. y aproximadamente a $5 \mathrm{~m}$. sobre el nivel del río, a 1,50 m de profundidad, en una mezcla de arenas rosadas, por encima de las cuales aparecen de abajo hacia arriba: arena amarilla friable, arena gris coesiva (inicio ocupación guarani), suelo gris oscuro, arena blanca, micro-suelo, y compactado.

Recursos litologicos: cantos rodados medianos (10 a $15 \mathrm{~cm}$ ) de meta-sedimentarias, agatas y ópalos.

Con excepción del sitio isleño los restantes están removidos por acción de los avances del río y por depredación antrópica, y se encuentran en las inmediaciones de la ciudad de Posadas. Además los pseudo-arqueológos y coleccionistas han retirado las puntas de proyectil más representativa y hoy integran colecciones privadas. Cabe destacar que se trata de zonas de campo en las que dominan comunidades herbáces donde aisladamente aparecen cerritos cubiertos por arboles pequeños.

Material común a los sitios descriptos: Instrumentos mono y bifaciales; en todos los sitios son más abundantes los instrumento sobre lasca que aquellos sobre núcleo. Entre los instrumentos bifaciales se destacan las puntas de proyectil triangulares, lanceolados, sin y con pedúnculo y con pedúnculo y aletas. 
Las proporciones de instrumentos entre si y de instrumentos respecto a lascas varía de zona en zona y sitio a sitio, siendo en todos los casos muy abundantes las lascas secundarias de diferentes tipos.

La materia prima varía acorde con los recursos litológicos.

En el Dpto. Iguazú estos grupos tuvieron contacto con otros de ceramistas portadores de la Tradición Taquara-Eldoradense (GIESSO op. cit.) y en el Dpto. Capital con agroalfareros de floresta Subtropical de Tradición Tupiguaraní (POUJADE op. cit.)

El patrón de asentamiento, el tipo de instrumental, las caracteristicas del ambiente ocupado por los cazadores-recolectores de Tradición Umbú, nos llevan a inferir que para la obtensión de proteínas habran desarrollado estrategias económicas dirigidas a la caza especializada y para conseguir carbohidratos, otras orientadas a la recolección de plantas y frutos silvestres.

\subsection{Cazadores-recolectores-agricultores portadores de la Tradición}

Taquara-Eldoradense (carta 10):

Esta tradición fue identificada por MENGHIN y WACHNITZ en 1956, en las inmediaciones del arroyo Piray Miní Dpto. Eldorado, el primero la denominó Cultura Eldoradense, y la ubicó en superficie y en estratigrafía.

Con posterioridad, fue reconocida por RISSO (op. cit.) en otros sitios a cielo descubierto de los Dptos Eldorado y San Ignacio y aislada estratigráficamente en una cueva (gruta 3 de Mayo) Dpto Gral. San Martín, y por GIESSO (op. cit.) en tres sitios a cielo descubierto (Unidad c): 2 sobre la margen derecha y uno sobre la margen izquierda del arroyo Urugua-f Dpto. Iguazú, donde también fueron ubicados estratigráficamente, con referencia a los tres últimos sitios, GIESSO especifica que los materiales están en sedimentos aluviales ácidos.

En Eldoradense se presentan tres patrones de asentamiento: dos a cielo descubiertos y uno bajo cielo cubierto

a. Ocupaciones a cielo descubierto:

a.a. Casas pozo y terraplenes, complementados con montículos funerarios (sitios trabajados por MENGHIN y luego por WACHNITZ).

a.b. Campamentos en los que las únicas estructuras identificables son fogones, sin poder definirse sectores específicos para determinadas actividades (Sitios detectados y trabajados por RISSO y GIESSO). 
b. Ocupaciones bajo cielo cubierto: gruta 3 de Mayo (Trabajada por RISSO). Los recursos litológicos predominantes son: basaltos y areniscas.

El nicho ecológico de Eldoradense es el monte mixto con araucaria y la selva subtropical.

Los sitios de Eldorado están en lomas con tierra colorada (lateritas), y en Iguazú tanto en tierra colorada como en sedimentos aluviales (con posibilidades para cultivos anuales).

Hasta el momento, uno de los elementos diagnósticos más representativo es la cerámica simples, consistente en pequeños pucos y ollas de bases redondeadas yvasos cónicos o cilíndricos, con predominancia de las formas verticales en las que el diámetro del cuerpo varía entre 8 y $20 \mathrm{~cm}$, apareciendo por orden de popularidad tiestos pulidos lisos de color cartanno-rojizo oscuro y otros grises, a los que se suman aquellos decorados con motivos geométricos: punteados formando líneas rectas paralelas, e incisos simples sobre superficies pulidas o alisadas, en algunos casos con impresión de cestería en la proción superior (cercana al borde).

El instrumental lítico asociado consiste en hachas alisadas (con y sin cuello para enmangue), manos de mortero, morteros planos, alisadores de cerámica, en algunos sitios materiales Altoparanaenses y en otros industrias semejantes a las descriptas para la gruta 3 de Mayo y para algunos de los sitios del urugua-í.

En función de las asociaciones y de los materiales aislados en estratigrafía, inferimos que los grupos hacedores de Eldoradense estuvieron en contacto con los cazadores-recolectores portadores de la Tradición Altoparanaense-Humaitá, de las industrias sin puntas líticas de 3 de Mayo y del Urugua-í y con los agricultores de floresta subtropical de tradición Tupiguaraní.

Tanto la tipología de los conjuntos (lítico y cerámico), como el nicho ecológico de los agricultores de Eldoradense, nos permiten inferir que sus portadores han desarrollado estrategias económicas adaptativas para la obtensión de proteínas, a partir de la caza, la pesca y la recolección de moluscos y de carbohidratos basados en la recolección de vegetales y en la agricultura.

3.5. Agricultores de Floresta Subtropical portadores de la tradición Tupiguaraní (carta 10):

En Misiones se detectaron numerosos sitios guaraníes:

a. A cielo descubierto: aldeas y cementerios (30 o 40) (MENGHIN, WACHNITZ, RISSO, PUJADE, GIESSO - op. cit.). 
b. Bajo cielo cubierto: campamentos en cuevas y aleros (304)-(RISSO, GIESSO, PUJADE op. cit.).

En la mayoría de los casos depredados por acción antrópica (coleccionistas, agricultura intensiva) o por avances y erosión de riós y arroyos.

En zona continental, las ocupaciones distan entre 200 y $700 \mathrm{~m}$ de las cauces tanto de los grandes ríos Paraná y Uruguay, como de sus principales afluentes, ubicándose entre 4 y $20 \mathrm{~m}$. sobre el nivel de las aguas y por encima de los 85 m.s.n.m..

En las islas paranaenses prospectadas (2), las aldeas están en la porción más elevada, 5 a $12 \mathrm{~m}$. sobre el nivel del agua y por encima de los 83 m.s.n.m., y los talleres líticos por debajo de la cota 80 .

En general los materiales y evidencias llegan hasta $10580090 \mathrm{~cm}$ de profundidad.

RISSO establece en base a 8 sitios ubicados en los Dptos Eldorado y San Ignacio la Fase Tabaí y sobre 3 sitios del Dpto Concepción las Fase Uruguay.

GIESSO identifica 2 sitios guaraníes con escaso material y muy perturbados, en el marco del Rescate Arqueológico del Urugua-í y excava un sitio en Pto. Victoria (Dpto. Eldorado), que lo vincula a la Fase Tabaí.

Nosotros en Rescate Arqueológico Yacyretá detectamos fuera de la cota de inundación 84 m.s.n.m., 20 sitios (Dptos Capital, Candelaria, y San Ignacio), removidos por agricultura intensiva o bien por fabricas de ladrillo, y en las islas paranaenses prospectadas (2) siete sitios: 3 en la Is. Corpus o Pindof (aún sin trabajar) y 4 en Is. Cañete o Itacuá (una aldea y tres talleres líticos), la aldea mide aproximadamente 150 $\mathrm{m} 2$ y de ellos excavamos $112 \mathrm{~m} 2$ y en los talleres-cantera que circundan la Is. y están sobre el manto basaltíco (lecho del río) efectuamos recolecciones superficiales sistemáticas. Si bien al momento no hemos determinado las vinculaciones con otros sitios de Ms., de Paraguay y de Brasil, cabe destacar que en la escavación practicada en la aldea identificamos fogones, y abundantes ocres ubicados zonalmente, además sobre un total de 10.257 tiestas, cuyo antiplástico (en general) es arena, obtuvimos las siguientes proporciones $97,98 \%$ liso simples, $1,17 \%$ unguicular complejo, $0,37 \%$ monocromo rojo, $0,27 \%$ cepillado y $0,20 \%$ corrugado, y sobre 11.614 piezas líticas la mayoría corresponden a desechos de talla, informaciones que nos permiten inferir, que los instrumentos iniciados en los talleres-cantera que circundan la Is., se concluían en la aldea.

A la fecha hemos iniciado el análisis tecno-tipologico en dos demos 3 talleres.

En M Cap. Is. Ca 1 (Ms. Dpto. Cap. Is. Cañete Sitio 1), recolectamos 128 piezas que comprenden grandes nucleos, Choppers, chopping-tools, raspadores toscos y lascas primarias. En M Cap. Is. Ca 3 rescatamos 518 litos que incluyen por orden de 
popularidad lascas medianas de diversos tipos, choppers, chopping-tools y raspadores toscos. Técnica empleada percusión directa-Materia Prima: Cuarcita roja.

Sobre la margen derecha del $\mathrm{R}$. Uruguay resulta muy importante la investigación de SEMPE (1980, iédita), quien trabajó varios sitios detectados en los Dptos. 25 de Mayo, San Javier y Oberá.

Apoyada en los sitios de San Javier en especial en una aldea campecina (que excavó en parte), aisló tipos cerámicos que los vincula con los recuperados en ocupaciones guaraníes del delta, y en base al material de los sitios de Oberá sefinió tipos cerámicos que relaciona con los exhumados en la zona del R. Paraná Panema medio y afluentes (decoración semejante a tipos Cambará); uno de estos sitios presentó evidencias de antropofagia (fragmentos de parietales humanos en un fogón) y arrojó el primer fechado por $\mathrm{C} 14$ para Misiones $1200+-90 \mathrm{dC}$.

Los sitios excavados por SEMPE también proporcionam datos botánicos y zoológicos.

Hicimos estos señalamientos particulares en el primer caso (sitios isleños) por tratarse de las primeras investigaciones en Is. realizadas en Ms.; y en el de las ocupaciones estudiadas por SEMPE, por las características de las informaciones que proporciona (antropofagía y fechado por $\mathrm{C} 14$, animales y vegetales asociados y estructuras de las aldeas).

Retomando los aspectos descriptivos generales de los asentamientos guaraníes: destacamos que en todos ellos están presentes en distintas proporciones las tres subtradiciones cerâmicas (pintada, corrugada y cepillada), agregándose los tipos lisos, en los que varían los antiplásticos, conforme con el ambiente utilizado.

Los recursos litológicos usados difieren de zona en zona, acorde con las disponibilidades del medio, y de los tipos de instrumentos, siendo los más comunes: en el $\mathrm{N}-\mathrm{NW}$ y NE el basalto, en el S-SW y SE las meta-sedimentarias y en ambos espacios geográficos con fines ornamentales: cuarzo y agatas.

Material lítico: hachas pulidas petaloides, bolas con zurco ecuatorial y sin él, bolas lenticulares, lascas trabajadas e percusión directa de distintos tamaños y tipos (primarias y secundarias) con retoques frontales y perimentrales, como así también instrumental sobre núcleo tembetás, pectorales, etc.

Los datos proporcionados por distintas investigaciones en sitios guaraníes, nos permiten inferir que en Ms., los agricultores de floresta subtropical de tradición tupiguaraní, desarrollaron distintas estrategias económicas para la obtensión de proteínas, concorde con las zonas ocupadas (inmediaciones de grandes ríos, o de afluentes de los mismos), y que los carbohidratos eran obtenidos tanto de la agricultura (maíz, mandioca, batatas, zapallos, porotos, maníes, etc.) como de la recolección. 
De ahí la aparición de distintos tipos de ocupación del espacio: a. A cielo descubierto: aldeas comunales semi-sedentarias, campamentos y sementerios.

b. Bajo cielo cubierto: campamentos temporarios en cuevas y aleros.

\section{POBLAMIENTO POST COLOMBINO (SITIOS DE FRONTERA). (CARTA 11).}

Misiones integra el área Platina y conjuntamente con Brasil Paraguay y Uruguay fue escenario de la implantación del sistema reduccional jesútico, y en ella se asentaron entre mediados del siglo XVII y primera década del siglo XVIII, las Misiones de Intapúa, San José, Candelaria, San Cosme y San Damián, Santa Ana, Loreto, San Ignacio, Corpus, Santa María del Iguazú, San Javier, Santa María la Mayor, Concepción, Mooroné, Martires, San José y Apóstoles. (carta 11).

Sobre estos sitios hay abundante información historiográfica proveniente de viajeros cronistas, Sacerdotes, y etnógrafos, referida a diversas ectividades Socio-culturales y económicas realizadas en su seno, como así también al funcionamiento político de esos poblados, y a la arquitectura que los caracteriza, más prácticamente están ausentes los estudios referidos a problemas generados por el contacto indio-europeo, y por el proceso de aculturación.

A partir de la década del 80 efectuaron relevamientos arquitectónicos por orden cronológico MAGGI 91980 y 1983) y GONZALES de HADDAD (1982 en adelante).

RISSO en 1970 prospectó y realizó pozos de sondeo en las reducciones de San Javier, Santa María da Mayor y Concepción de la Sierra, adscribiendo el material recuperado a la Fase Misiones de Brasil; GIESSO hizo lo propio en Santa Ana y Loreto, desconocemos sus resultados, y sustentados en la información histórica, GIESSO y ROLON prospectan las zonas donde acorde con ella se implantó Nuestra Señora del Iguazú (GIESSO op. cit, ROLON 1988) y nosotros el espacio donde la historiografía ubica las dos Mooroné (hasta el momento no hallamos evidencias).

ROVIRA, en el marco del Rescate Arqueológico Macyretá, accedió al Doctorado en Ciencias Naturales orientación Antropológica con un trabajo de Arqueología Histórica en la Reducción de Nuestra Señora de la Candelaria (inédito) el cual se centra en los procesos culturales identificados en el sitio MC - M1 (Misiones Dpto. y Muncipio Candelaria Misión sitio 1), propone entre otros un sistema de organización de los datos comparativos para el estudio de los procesos Socio-culturales desarrollados en el Area Platina, y a partir del perfil arqueológico de MC - M1 proporciona 
datos para la definición del Patrón Arqueológico de frontera que podría caracterizar a las Reducciones Jesuíticas de Guaraníes.

Respecto a la puesta en valor y conservación de los sitios de Frontera, cuya expresión más destacada es la arquitectura monumental resaltamos que la Comisión Nacional de Museos, Monumentos y Sitios ha intervenido en San Ignacio Miní en la década del 40 , sin trabajo sistemático de arqueología, y a la fecha la conserva precariamente, y esporadicamente efectúa el mantenimiento en Santa María la Mayor, también sin labores de arqueología sistemática.

A su vez la Provincia en la década del 80 encaró la limpieza e Inventario de Santa Ana y Loreto (Arq. Mary González de Haddad), hoy abandonadas y en el marco del Rescate Yacyretá la Art. de mención efectuó el inventario de Candelaria (Inédito), y el Lic. AMAT el estudio de vegetales que afectan las rocas que fueron utilizadas para las construcciones de San Ignacio Miní (también Inédito).

\section{OCUPACIONES ETNOGRAFICAS (CARTA 12).}

En los Dptos San Ignacio, Libertador General San Martín y Montecarlo, los asentamicntos Guaraníes cercanos a la cuenca del R. Paraná, están ubicados en las inmediaciones de sitios indígenas con materiales de tradición Tupiguaraní o bien superpuestos a ellos.

\section{CONSIDERACIONES FINALES:}

En el presente trabajo, utilizamos esquemas cronológico-culturales elaborados por otros investigadores, sin abordar esta problemática, por cuanto consideramos que, antes de plantear otras propuestas, es menestrar contar con nuevas investigaciones que incluyan el NE y SE de Ms., prácticamente desconocidos desde el punto de vista arquiológico. Estudios que además de los análisis cuali-cuantitativos de las regularidades o variabilidades de los conjuntos, y su ubicación estratigráfica, contemplan los procesos culturales de formación de los depósitos y en la medida de lo posible incorporen fechados por $\mathrm{C} 14 \mathrm{y} / \mathrm{o}$ por termoluminiscencia.

Basádonos en la arqueología (tipos de contextos, patrones de asentamiento, hipótesis acerca de funciones de los artefatos y estrategias de subsistencia), apoyados en la Historia (viajeros, cronistas, etc.), y en las Ciencas Naturales (determinaciones 
de diversos habitats), identificamos en Ms. a partir de tiempos pre-colombinos 5 processos socioculturales indígenas fuertemente condicionados por los habitats que les dieron sustento, de los cuales cuatro son autóctonos de las Tierras Altas Orientales y uno alóctono, y entre los siglos XVII y XVIII un sexto proceso que responde a intereses extra-continentales.

Circunscribiendonos a los esquemas cronológico-culturales en vigencia para Ms. establecemos:

6.1. Un proceso autóctono más antiguo identificado con la tradición Altoparanaense-Humaitá (carta 9) que se desarrollo fundamentalmente en espacios cercanos a cursos de agua, del Distrito de los Laureles (donde aparece la mayor concentración), Fluvial (Subdistritos Paranaense y Uruguayense) y Distrito de los helechos arborescentes (carta 7), y en suelos 2, 3, y 7 (carta 8).

Este proceso dinámico, provablemente experimentó cambios substanciales en el NW por los contactos de sus portadores con grupos cazadores-recolectores-agricultores de tradición Eldoradense-Taquara y en las zonas mediterráneas y centro E por sus vinculaciones con los agricultores de floresta subtropical de tradición Tupiguaraní. Los datos históricos no son claros respecto al contacto de los Altoparanaense con los europeos, no existiendo en Ms. evidencias arqueológicas demonstrativas de esta relación.

6.2. Un segundo proceso cultural expresado por las Industrias de 3 de Mayo (carta 9) se desenvolvio en zonas cercanas a importantes arroyos subtropicales que desaguan en el R. Paraná, en el Sector Misionero Distrito de los Laureles (carta 7), en suelos 7 (carta 8).

Este proceso igualmente dinámico, durante sus últimos etapas habría experimentado cambios importantes provenientes del contacto de sus artífices con grupos de cazadores-recolectores-agricultores de tradición Eldoradense-Taquara.

$\mathrm{Ni}$ los materiales arqueológicos recuperados en Ms., ni la historiografia consultada, dan información acerca de vinculaciones entre los portadores de las industrias de 3 de Mayo y los grupos Tupiguaraní o entre los primeros y los europeos.

6.3. Un tercer proceso cultural reconocido en la Tradición Umbú (carta 9) se desarrolló fundamentalmente en el distrito de los campos del Sur y en Sabanas altas del Distrito de los Laureles (carta 7), su cultura material se recupera directamente sobre el lecho basaltico del R. Paraná y en sedimento aluviales suelos 1, 2, 7 y 9 (carta 8).

Este proceso habrá seguido distintas direcciones acorde con los contactos establecidos por sus responsables. 
La información arqueológica permite constatar las relaciones de estos grupos con los de tradición Taquara-Eldoradense en el NW y con los de tradición Tupiguarani en el SW, y la historiografía provee datos acerca de los tipos de vinculaciones instituídas con los europeos.

6.4. El cuarto proceso cultural, manifesto en la tradición Eldoradense-Taquara (carta 10), instaura la agricultura tanto en el Sector Misionero Distrito de los Laureles, como en el Sector Planaltense (carta 7), en lomes de tierras rojas y en sedimentos aluviales suelos tipos 3,5 , y 7 (carta 8).

$\mathrm{Al}$ iniciarse este proceso, sus responsables estuvieron en contacto con los grupos de cazadores-recolectores que dieron origen a los procesos 1,2, y 3 , en su período final con los agricultores de floresta subtropical de tradición Tupiguaraní.

Hasta el momento, desconocemos si tuvieron algún tipo de vinculación con la población europea de época colonial.

6.5. El quinto y último proceso indígena que consignamos se reconoce en la tradición Tupiguaraní (carta 10), sus responsables son grupos pertenecientes a la etnía Guaraní, los que acorde con informaciones arqueológicas, histórica, etnográfica $\mathrm{y}$ un fechado por $\mathrm{C} 14$ ingresaron a Misiones en el siglo XIII.

Estos grupos de agricultores de floresta subtropical ocuparon las inmediaciones de los grandes ríos y arroyos del Sector Misionero (carta 7) utilizando suelos 2,3, $5,6,7$ y 8 (carta 8$)$.

Acorde con las zonas sobre las que avanzaban establecieron contactos con los cazadores-recolectores que desarrollaron los procesos 1 a 3 y con los agricultores-cazadores-recolectores que instauraron el proceso $4 \mathrm{y}$ en sus etapas finales con los europeos que iniciaram el reconocimiento del territorio misionero por una parte, y por otra con los misioneros de la compañía de Jesús que los sometieron a la sociedad europea.

6.6. El sexto proceso socio-cultural identificado responde a intereses extra-continentales y corresponde a la aculturación impuesta por el Sistema Jesuítico, identificado con los poblados misioneros (Sitios de Frontera), y en zonas aledañas con los tiestos hispano-indígenas, entre otros (carta 11), se desarrolla fundamentalmente en los campos del Sur (carta 7).

\section{BIBLIOGRAFIA:}

ALTENFELDER SILVA, F. y MEGGERGS, B.

1984: Cultural developmen in Brasil - Smithsonian Miscellaneous Collections V. 146, nro. I; pp 119/129; Washington.

En C. A. 


\section{ALVAREZ KERN, Arno}

1982: Paleo, Paisagens e Povoamento Pré-histórico do Río Grande do Sul

1984: O proceso histórico platino no século XVII, da aldeia guaraní ao povoado missionciro Folia Hist. del Nordeste nro. 6, Inst. Hist. Fac. Hum/UNNE; Resistencia.

En C. E.

AMBROSETTI, Juan Baustista

1892a: Rápida ojeada sobre el territorio de Mnes - Boletín del Inst. Geog. Arg. Tomo XIII, Cuadernos 3, 4, 10, 11, y 12 Bs.

As. En B.C.E.H.C.

1892b: Viaje a las Misiones Argentinas y Brasileras por el Alto-Uruguay. Publicación del Museo, La Plata.

En B.C.E.H.C.

1893a: Rápida ojeada sobre el Territorio de Mnes - Imprenta de Martín Biedma, Bs. As. En B.C.E.H.C.

1893b: Materiales para el estudio del Folklore Misionero - Rev. del Jardín Zoológico, Tomo I pp. 129/160, Municip. de Bs.

As. En. B.C.E.H.C.

1894a: Los indios Kaigángues de San Pedro (misiones) - Rev. del Jardín Zoológico, pp. 305/387; Municip. de Bs. As.; Bs. As.

En B.C.E.H.C.

1895a: Los indios cainguá del Alto Paraná (Misiones) - Inst. Geog. Arg. Tomo XV, pp 661/751;

Bs. As.

En. B.C.E.H.C.

1895b: Los cementerios prehistóricos del Alto Paraná - Boletín Inst. Geog. Arg. Tomo 16, 5/8, pp 1/36, Imp. Roma, Bs. As.

En C.A.

1986: Tercerviaje a Misiones_Boletín del Inst. Geog. Arg. Nro. 9 al 12 y 16, pp 391/533, Imp.

Roma, Bs. As.

En. B.C.E.H.C.

ARANDA, Domingo

1964: Monografía sobre Suelos de la Provincia de Misiones. INTA Cerro Azul. Mnes.

BOROS, Diego de

1892: Noticias de algunas Reducciones de la Comapñía de Jesús en las Pcias. del Paraná y

Uruguay 1637 - Rev. del Archivo Gral. de Bs. As., tomo IV, pp 27/94, Bs. As.

En B.C.E.H.C.

BRABO, Francisco Javier:

1872: Inventario de los bienes hallados a la expulsión de los Jesuítas. Ed. Madrid, 672 p.

1872: Colección de documentos relativos a la expulsión de los Jesuítas de la Rep. Arg. y Paraguay en el reinado de Carlos III - Tipog. José Ma. Pérez, Madrid.

En B.C.E.H.C. 
BROCHADO, José P.

1969: Dados parciais sobre a arqueología do vale do Ijui - Publicaçōes Avulsas do Museu Paraense "Emilio Goeldi", 13, pp 31/57, Belem. En C.A.

1971: Extensao das pesquisas arqueológicas nos vales do Jacui/Mirim - Publicaçōes Avulsas do Museu Paraense "Emilio Goeldi", 15, pp 11/32, Belem. En C.A.

1974: Pesquisas arqueológicas no escudo cristalino de Rio Grande do Sul (serra Sudeste) Publicações Avulsas do Museu Paraense "Emilio Goeldi", 26, pp 25/51, Belem.

En C.A.

BROCHADO, José P. y otros:

1969: A cerâmica das Missōes Orietais do Uruguaí/ Un estudo da aculturação indígena através da mudança na cerâmica - Pesquisas, Antropologia Nro. 20, pp 169/210, Inst. Anchietano de Pesquisas, Brasil. En. B.C.E.H.C.

BRUXEL, Arnaldo; S. J.

1958: A nobreza dos caciques guaranís do primitivo Rio Grande do Sul - Pesquisas, II, I, pp 81/112 Porto Alegre.

1984: Los treinta Pueblos Guaraníes. Panorama Histórico-Institucional. Ed. Montoya. 134 p. ilust.

BURNA, Ernesto A.

1984: Un paradero Guaraní en la zona de Pto. Laharrague. Mnes. IV Encuentro de Geohistoria Regional, pp 85/100; Resistencia

BUSCHIAZZO, Mario J.

1940: La Arquitetura Jesuítica en la Argentina. "La Prensa". Bs. As. 29 Dic.

1940: Informe sobre la misión jesuítica de San Ignacio Mini-Boletín de la Comisión Nac. de Museos y Mntos. Hist. Año 6, Nro. 6, pp. 128/136; Bs. As.

En B.C.E.H.C.

CABRAL, Salvador

1978: La Organización social de los Guaranies y las misiones. En Megafón nro. 7 Edit. Castañeda. Bs. As.

En C.E.

CAMBAS, Anibal

1940: Paraderos y Enterratorios Guaraní - Boletín junta de Estudios Históricos de Misiones, 2; pp 8/9; Posadas.

En C.A.

1962: Los antiguos guaraníes del Alto Paraná - Art. Graf. Gendarm. Nac.; San Ignacio.

En B.S.

1967: Mayntzhusen y los indios guayakies. Separata del suplemento Antropológico de la Revista del Ateneo paraguayo. Vol. 2 Nro. 2. Asunción.

En C.E.

1969: Las Misiones del Paraná, Uruguayy Tape - investigacionesy Ensayos Nros.6/7, pp 99/121, Acad. nac. de la Historia; Bs. As.

En B.C.E.H.C. 
1970: Breve Cronología Histórica de la Ciudad de Posadas. Comisión Central Ejecutiva del Primer Cientenario de la ciudad de Pdas. 2 - páginas.

\section{CAMBAS, Graciela}

s/f. Sobre Ache Guayaqui; El jamo ancestral - Mimeog.; s/d.

En. A.G.K.

1984: El arte guaraní, Edit. Ateneo Cultural Folklórico de Mnes., Misiones. En C.E.

CARUGO, Esteban

1979: Las Ruinas Jusuíticas de Ntra. Sra. de Santa Ana. Ed. UNaM.

CARVALLO, Casiano N.

1980: Síntesis de historia de la Prov. de Misiones (contribución de los jesuíticas a la formación histórica de Misiones) - Ed. Montoya; Posadas.

En B.C.E.H.C.

1983: Historia cartográfica de Misiones - Ed. Montoya; Posadas.

En B.C.E.H.C.

\section{CHMYZ, Ygor}

1967a: Dados Parciais sobre arqueología do vale do río Paranapanema - Publicacoes Avulsas do Museu Paraense "Emilio Goeldi" 6; pp 59/73; Belem.

En C.A.

1967b: O sítio arqueológico PRUVI (Abrigo sob rocha Casa de pedra) Cadernos de Arqueología 1; Paranaguá.

En C.A.

1968: Novas Perspectivas de Arqueología Guaraní no Est. Paraná - Pesquisas Antropología Nro. 18, pp 171/189; São Leopoldo.

En B.C.E.H.C.

1969a: Dados parciais sobre arqueología do rio Ivai - Publicaçōes Avulsas do museu Paraense "Emilio Goeldi" 10; pp 95/114; Belem.

En C.A.

1969b: Pesquisas arqueológicas no alto y medio rio Iguazú - Public. Avulsas do Museu "E. Goeldi" 15, pp 103/125; Belem.

En C.A.

1971: Pesquisas arqueológicas en el medio y baixo rio Iguazú public. (lic. Avulsas do Museu "E. Goeldi" 15, 87/108; Belem.

En C.A.

1974: Dados arqueológicos do baixo ríos Paranapanema e do Alto rio Paraná - Public. Avulsas do Museu - "E. Goeldi" 26; pp 67/90; Belem.

En C.A.

1976: Arqueología e Historia da Vila Espanhola de Cidade Real do Guairá (1) - Cadernos de Arqueología 1, Paranaguá.

En. C.A.

1976/Proyecto Arqueológico Itaipú:

19831976 - Primer Relatorio; Curitiba

1976/77 Segundo Relatorio; Curitiba 
1977/78 Terceiro Relatorio; Curitiba

1978/79 Cuarto Relatorio; Curitiba

1979/80 Quinto Relatorio; Curitiba

1980/81 Sexto Relatorio; Curitiba

1981/83 Septimo Relatorio; Curitiba

En C.A.

1981: Relatorio das pesquisas arqueológicas realizadas na Area da Usina Hidroeletrica do Salto Santiago (1979/80); Florianopolis/Curitiba.

En C.A.

1984: Projeto arqueológico Rosana - Tacuarucú. Convenio da Fundaçẫo UFPR CESP., Curitiba.

En. C.A.

DOBLAS, Gonzalo de.

1836: Memoria histórica geográfica, política y económica sobre la Provincia de Misiones de Indios Guaraníes. Bs. As. 116 pp. En D'Angelis. Colección III.

\section{DIMITRI, J.M.}

1980: Flora arbórea del Parque Nacional Iguazú Bs. As. 1974. Enciclopedia Argentina de Agricultura y Jardinería T 1 - Segundo Volumen. Ed. ACME BS.AS. Primer Volumen.

ELDORADO, (revista)

1977: (Antropología guaraní-Notas breves sobre la cultura aborígen altoparananese) año 1 , nro. 3; Eldorado.

En C.E.

GIESSO, Martín

1984: Excavaciones arqueológicas en un sitio guaraní en cueva Eldorado (Mnes) - Actualidad Antropológica, 20; pp 32/33; Olavarria. En. C.A.

1985a: Estado actual de las investigaciones arqueológicas en Misiones; El tupiguaraní del Alto Paraná, Mnes./Arg. - Presentado en VIII Cong. Nac. de Arq. Arg. Concordia. En C.A.

1985b: Registro arqueológico de ocupación de cuevas y aleros por grupos tupiguaraní en el Alto Paraná, Mnes./Arg. Presentado en VIII cong. Nac. Arq.; Concordia. En. C.A.

1985c: Contacto hispano-indígena en el norte de Misiones; primeras evidencias arqueológicas - Presentado en VI Encuentro de Geohistoria Reg.; Posadas.

En. C.A.

1986/7: Proyecto de Relevamiento y Rescate Prehistórico e Histórico en la Cuence del Aprovechamiento Hidroeléctrico del Arroyo Uruguaí - Informes 1, 2, 3, 4, y 5 inéditos.

GIESSO, Martín y POUJADE, Ruth A.

1986: Proyecto de Relevamientop y Rescate Prehistórico e Histórico en la cuenca del aprovechamiento hidroeléctrico del arroyo Uruguaí - Arqueología 5; pp 91/102; Curitiba.

En. C.A.

GIESSO, Martín - POUJADE, Ruth Adela, AQUINO de CRICEL, Lastenia J. 
1986: Aportes desde la Arqueología y las Ciencias Naturales a la idea de Región - Jornada Anual de Investigaciones; Instituto de investigaciones; Facultad de Humanidades y Ciencias Sociales; Misiones 11-42 pgs.

GIESSO, Martín y RISSO, Antonia.

1985a: Puerto Victoria; Un sitio Tupiguaraníen el Alto Paraná, Mnes. Arg. Ymaguaré, Revista del Museo Munic. 1; pp 5/28; Eldorado.

En C.A.

1985b: Primer informe sobre excavaciones arqueológicas en el sitio Puerto Piray I; su componente lítico y su componente cerâmico Presentado en VIII cong. Nac. Arq. Arg.; Concordia.

En. C.A.

GONZALEZ de HADDAD, Mary

1983: Reducciones Jesuíticas de Guaraníes y Parque Nacional Iguazú. Presentación efectuada ante el Comité de Patrimonio Cultural Mundial de Naciones Unidas. Bs. As. Dirección General de Cultura de la Provincia de Mnes. 256 p. ilust.

1984: Las Ruinas de Ntras. Sra. de Santa Ana. Primeras Jornadas Internacionales de Mnes. Jesuíticas. Resistencia. direc. Gral. de Cultura de la Pcia. de Mnes. 51 p. (inédito).

GUTIERRES, Ramón

1974: Estructura socio-política, sistema productivo y resultante espacial en las Mnes. Jesuíticas del Paraguay - s/ed; Asunción.

En B.C.E.H.C.

LAFON, Ciro René

1971: Introducción a la Arqueologia del Nordeste Arg. Relaciones de Soc. Arg. de Antrop. XX, v (2); pp 119/152; Bs. As.

1972: El replanteo de la Arqueología del Nordeste Arg. - Antíquitas XIV; pp 1/16; Bs. As.

En. C.A.

MAGGI, Gustavo

1981: Estado Actual de los Conjuntos Jesuíticos en Misiones. Dirección Gral. de Cultura y UNaM.

1984: Los Conjunto Jesuíticos de Misiones. Dirección Gral. de Cultura. Mnes.

MARTINEZ, Crovetto R.

1963: Los Estudios Taxonomicos Biométricos. Schnus molle y S. areira.

1963: Esquema Fitogeográfico de la Provincia de Misiones. BONPLANDIA. Tomo $1 \mathrm{n}^{\circ} 3$ (Biblioteca Univ. Nac. de la Plata).

1965: Estudios Ecológicos de los Campos del Sur de Misiones. Boplandia II Nro. 2.

1968: "Introducción a la Etnobotánica aborigen del NE Argentino" ETNOBIOLOGICA UNNE - Fac. de Agronomía y Vterinaria Ctes. Rep. Arg. $n^{\circ} 11$

1968: "Notas sobre la Agricultura de los indios Guaraníes (Rep. Arg.) Etnobiologica - UNNE

- Gac. de Agronomía y Veterinaria. Ctes. Rep. Arg.

1981: Plantas utilizadas em Medicina en el N.O. de Corrientes. Miscelandia 6 Lilos.

MAYNTZHUSEN, Federico C. 
1910/2: Uber vorkolumblanische Siedenlungen und Urnenfriedhofeder Guaraní em Alto Paraná - XVII Cong. Int. de Americanist. 2; pp 453/463; Bs. As. EN. C.A.

1941: Las cerámicas de los Paradores prehistóricos del Alto Paraná-Boletín Junta de Est. Históricos de Mnes. 2; pp 5/7; Posadas.

En C.A.

1944: Estudio de un cráneo de un supuesto cacique guaraní, encontrados en urna funeraria del paradero y puerto de Yaguarararapá, Alto Paraná - Boletín Junta de Est. Históricod de Mnes. pp. 7; Posadas. En. C.A.

MENGHIN, Osvaldo F. A.

1955/6: El Altoparanaense - Aspurias, tomos XVII y XVIII, pp 172/200; Barcelona.

En. B.C.E.H.C.

1960b: Observaciones sobre la Arqueología Guaraní de Arg. y Paraguay. Jornadas Internacionales de Arqueología y Etnografía 50; pp 54/68.

1961: Dos notables formas de hachas neolíticas de Misiones (Rep. Arg.) Homenaje a P. Martinez del Río - P. 103/111; Mexico.

En C.A.

MENTZ RIBEIRO, Pedro Augusto

1975: Os abrigos sob rocha do Virador no Estado do Río Grande do Sul Brasil. Nota Previa Revist do CEPA 2; pp 25; Santa Cruz do Sul. En C.A.

1978: Cerámica Tupiguaraní do vale do Río Pardo - Revista do CEPA - 6; pp 54; Santa Cruz do Sul. En. C.A.

1980: Casas subterraneas no Planalto Meridional Municipio de Santa Cruz do Sul, Rio Grande do Sul - Revista 9, pp 52; Santa Cruz do Sul. En C.A.

1983a: O Tupiguaraní no vale do Río Pardo e a Reducao Jesuítica de Jesus - Ma. - Revista do CEPA, 10; pp 172; Santa Cruz do Sul.

En. C.A.

MENTZ RIBEIRO, Pedro A. y Otros.

1976: A redução Jesuítica de Jesús Ma. Candelaria/Rio Grande do Sul. Nota Previa-Revista do CEPA 4; pp 43; Santa Cruz do Sul.

En. C.A.

1977: A acorencia de zoolitos no planalto meridional; Barros Cassal, RS/Brasil - Revista do CEPA 5, pp 5/38, Santa Cruz do Sul.

En. C.A.

1979: Sitios Arqueológicos da tardição Taquara Fase Erveiras, no vale do Río Pardo RS, Brasil

- Nota Previa - Revista do CEPA, 6, pp 60; Santa Cruz do Sul.

1982: A ocupação de locais cobertos pelo tupiguarani no vale do Río Pardo RS - Revista do CEPA 11, pp 7/31; Santa Cruz do Sul.

En. C.A.

1985: Levantamientos arqueológicos no municipio de Esmeralda, Río Grande do Sul/Brasil Revista do CEPA 12 (14), pp 49/105; Santa Cruz do Sul.

En. C.A. 
1986a: Levantamientos Arqueológicos no vale dos Rios Camaquá e Irapúa, RS/Brasil - Revista do CEPA 13 (15), pp 41/70; Santa Cruz do Sul.

1986a: Projeto Arqueológico de Salvamento na Regio de Boa Vista Territorio de Rórarima, Brasil - Primera etapa de campo nota previa - Revista do CEPA 13 (16), pp 33/60; Santa Cruz do Sul.

En. C.A.

1987: Protejo Arqueológico de Salvamento na Região de Boa Vista Territorio de Rorarima, Brasil - Primeira etapa de campo (1985) - Revista do CEPA 14 (17), pp 82; Sánta Cruz do Sul.

En. C.A.

MATRAUX, Alfred

1927: Les migrations Historiques des Tupiguaraní - Journal de la Societe des Americanistes, N.S., vol. XIX; Paris.

En. R.A.

1928a: La civilización materelle des tribus Tupiguaraní-Lib. Orientaliste Paul Geuthner; Paris. En. R.A.

1928b: La religión des Tupinambá et ses repports avec celle des outre tribus Tupiguaraní - Lib. Ernest Leroux, Paris - También, A religión dos Tupi-Nambá ... Ed. Brasiliana 267; Sao Paulo (1950).

En. B.G.

1931: Les hommes-dieux cher les guaranies - Rev. Del Inst. De Etnología. Univ. Nac. de Tucumán, Tomo II, Ira. entrega; pp 70/80; Tucumán.

En. B.C.E.H.C.

1974: Migraciones Históricas de los Tupiguaraní - Univ. Nac. del Nordeste; Resistencia. En. B.C.E.H.C.

MILLER, Eurico T.

1967: Pesquisas Arqueológicas efectuadas no nordeste do Río Grande do Sul - Public. Avulsas do Museu Paranaense "E. Goeldi" 6, pp 15/25; BELEM, En. C.A.

1969a: Pesquisas Arqueológicas efectuadas no noreste do Río Grande do Sul (Alto Urugua-1) - Publicaciones Avulsas do Museu Paranaense "E. Goeldi" 10, pp 33/46; Belem. En. C.A.

1969a: Pesquisas Arqueológicas efectuadas no oeste do Rio Grande do Sul. Public. Avulsas do Museu Paraense "E. Goeldi" 13, pp 11/21; Belem.

En. C.A.

1971: Pesquisas Arqueológicas efectuadas no planalto meridional Rio Grande do Sul (Rios Urugua-i, Pelotas e Antas) - Publicaciones Avulsas do Museu Paranaense "E. Goeldi" 15, pp 37/60; Belem.

En. C.A.

MONTOYA, Antonio Ruiz de

1639: Conquista esperitual hecha por los religiosos de la Cía de Jesus en las provincias del Paraguay, Paraná, Uruguay, y Tape - Madrid - (reed. Bilbao, 1892).

En. B.G. 
1639b: Tesoro de la lengua guarani-Madrid (Reed. Facsim. Leiprig. 1876).

En. B.G.

MOERNER, Magnus

1968: Actividades económicas y políticas en el Río de la Plata Ed. Paidos; Bs. As.

En. B.C.E.H.C.

MOUSSY, Martín de

s/f Memoria histórica sobre la decadencia y ruina de la Mnes. Jesuítica en el seno del Plata s/ed.

En. B.C.E.H.C.

MUJICA, Juan Ignacio

1986/7: Proyecto de Rescate Arqueológico Yacyretá Prov. de Corrientes Arg. ler. y 2do. informes de avance, inédios.

En. C.A.

NUÑEZ RUIZ DIAZ, Carlos Eduardo

1977: Primera noticia sobre yacimientos arqueológicos de Puerto Piray UNaM, Posadas.

En. B.C.E.H.C.

PALAVECINO, Enrique

1977: Los Guaraníes del Delta del Paraná y del Norte, en areas y capas culturales en el territorio argentino _ Museo de Hist. Nat. de San Rafael; Mendoza.

En. B.C.E.H.C.

PERAMAS, José

1947: La República de Platón y los guaraníes Bs. As. 224 p.

PERIE DE SCHIAVONI, Angela

1979a: Prehistoria de Misiones _ Rev. Ediciones Educt. año 1, nro. 1 - Fund. H. T. Pérez; Posadas.

En. B.S.

1979b: La Cultura Guaraní - Rev. Ediciones Educt. año 1 - nro. 2, Fund. H.T. Pérez; Posadas. En. B.S.

POPESCU, Oreste

1984: El sistema económico en las Misiones Jesuíticas - PampaMar - Bahía Blanca.

En. B.C.E.H.C.

POUJADE, Ruth Adela

1985/6: Proyecto integral para la recuperación del Patrimonio Cultural prehistórico de las zonas a inundarse en el Municipio de Posadas (Mnes-Arg.), por el emprendimiento Hidroeléctrico Yacyretá Cuatro Informes, inéditos.

En. C.A.

1986/7: Programa de Relevamiento, Rescate e Investigación Cultural y Natural en Zonas Afectadas por E.B.Y. en Misiones - tres informes de Avance, Inéditos.

En. C.A.

1980: Relevamiento arqueológico generalizado de la Provincia de Mnes. Expediente 200DGC.; Posadas inédito. 
1986: Proyecto arqueológico Yacyretá. Informe sumario de la Primera Etapa de Relevamiento y Rescate en Municipio de Pdas. Arqueología 5, pp 79/90; Curitiba.

En. C.A.

1988: Relevamiento, Rescate e Investigación Cultural Y Natural en Zonas afectada por la E.B.Y. en Misiones (R.A) 227 pags.; Posadas.

RIZZO, Antonia

1967: Primeras noticias sobre excavaciones estratégicas de una gruta en Tres de Mayo, Garuapé/Mnes. Anales de Arqueol. y Enol. 20; p;p 77/92; Mendoza.

En. C.A.

1968a: Un Yacimiento arqueológico en la Provincia de Mnes. La Gruta de Tres de Mayo - Tesis Doctoral _ Univ. Nac. de Rosario, mimeografía.

En C.A.

1968b: Hallazgos arqueológicos efectuados en un yacimiento en gruta, Tres de Mayo, Mnes./Arg. Pesquisas Antropología 18, pp 11/19; São Leopoldo.

En. C.A.

1968c: Distribución de Sitios Arqueológicos en el Dpto. de Eldorado Mnes. Pesquisas Antropologia 18 pp 131/134; São Leopoldo. En. C.A.

1969: Nuevas Investigaciones arqueológicas en la Prov. de Mnes. Antiquitas 9, pp 6/9; Bs. As. En. C.A.

1979/80: Prehistórica de Misiones. Aportes de Menghin a la mismay resultados obtenidos en Invest. posteriores - Sapiens 4, pp 57/63; Chivilcoy.

En. C.A.

ROVIRA, Beatriz

1989: Arqueología Histórica del Conjunto Jesuítico de Ntra. Sra. de la Candelaria, Provincia de Mnes. (Tesis Docotoral Inédita) (2 Tomos).

RUIZ de MONTOYA, Antonio s.j.

1892: La Conquista espiritual hecha por los religiosos de la Cía de Jesús - Imp. del Corazón de Jesús; Bilbao.

En. B.C.E.H.C.

SCHIMITZ, Pedro Ignacio

1959: A ceramica guaraní da ilha de Santa Catarina e a cerâmica da Base Area - Pesquisa III, pp 267/324; Porto Alegre.

En. B.G.

1981: Arqueología del Nordeste Arg. y del Sur de Brasil en la visión del Dr. O.F.A. Menghin y de otros arqueólogos posteriores Pesquisas Antropología 32, pp 207/223.

En. C.A.

1984: Caçadores e colectores de pré-historia do Brasil (segunda copia). Inst. Anchietano de Pesquisas. UNISINOS; Săo Leopoldo. En. C.A.

SCHIMITZ, Pedro I. y BROCHADO, José P.

1981a: Datos para una secuencia cultura del Estado de Rio Grande do Sul Brasil - Pesquisas Antropología 32, pp 131/160; São Leopoldo.

En. C.A. 
SEEP, Antonio

1971: Relación de viajes a las Misiones Jesuíticas - Eudeba; Bs. As.

En. B.C.E.H.C.

STORER, Tracy I. y USINGER, Robert.

1950: Zoología General Ed. Omega S.A. Barcelona;

TORRES, Luis Ma.

1913: Los Primitivos habitantes del delta del Paraná; Bs. As.

En. B.G.

WACHNITZ, Germán A.

1969: Enfoques históricos sobre las antiguas misiones - Comis. de festejos del Cincuentenario; Eldorado.

En. B.C.E.H.C.

1984: Prehistoria Altoparanaense Pre-Guaraní - s/ed; Eldorado.

En. C.A.

NOTA:

FAUNA: Especies comunes a todos los ambientes. En el N mayor número de especies, en el S. menos especies más ejemplares.

- UNIVERSIDAD NACIONAL DE MISIONES ARGENTINA 
CARTA 1 -

Ubicecion de Misiones en in Pej10.-

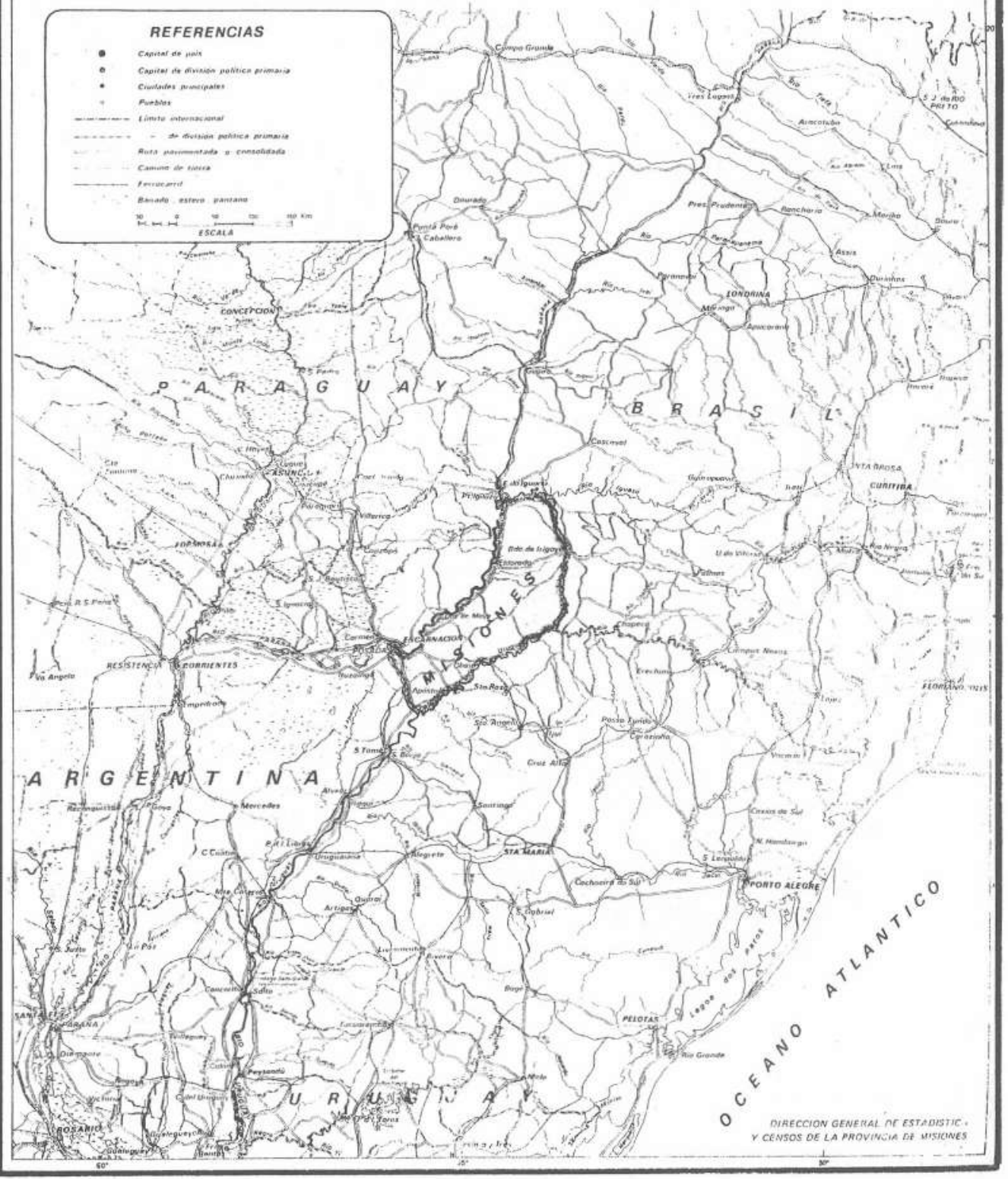


CARTA 2 -

Divisio : olficr.-

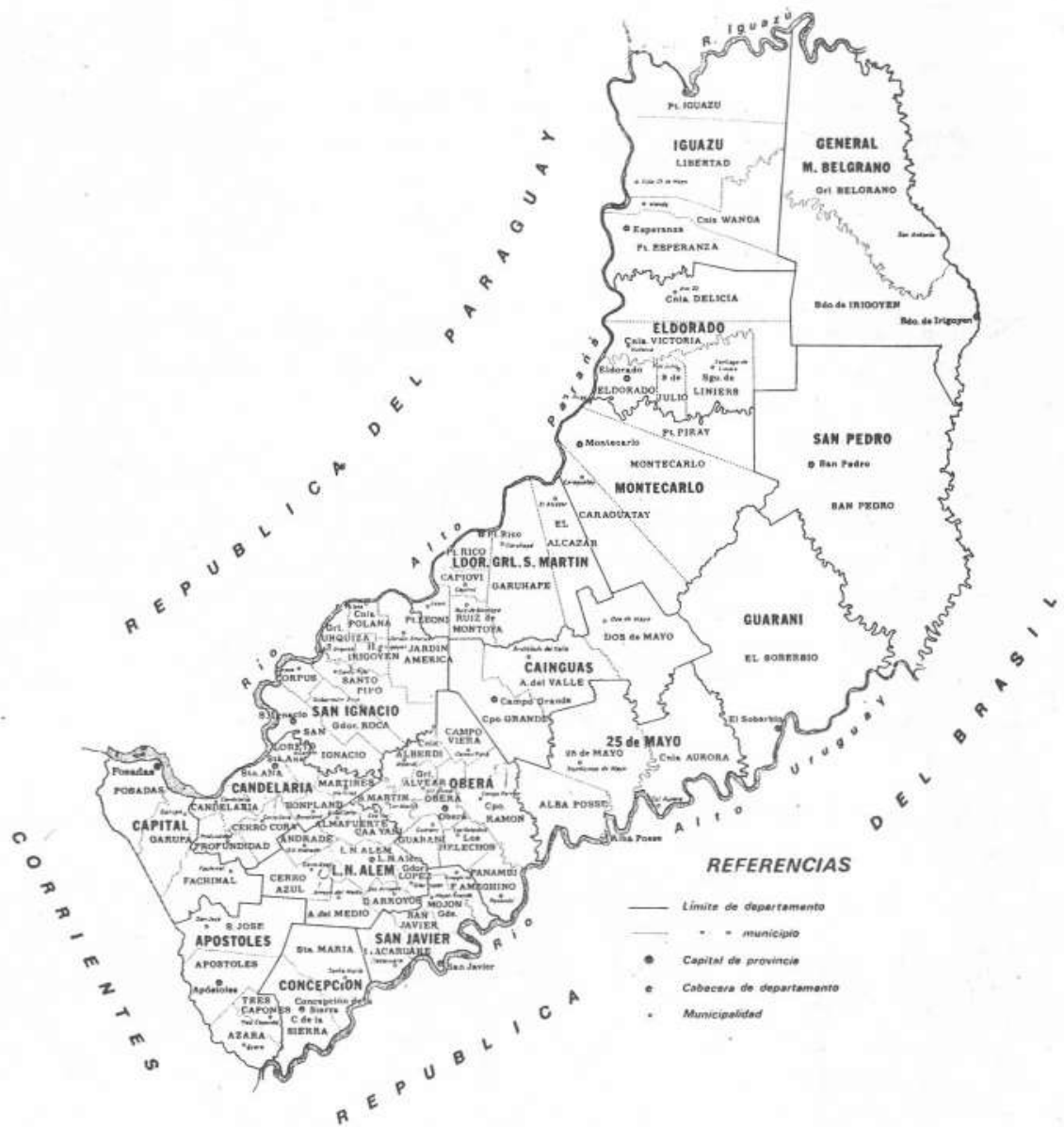

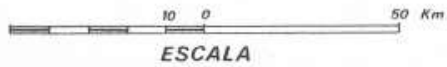


CARTA 3 -

Eardecteristices de1 swouk10.-

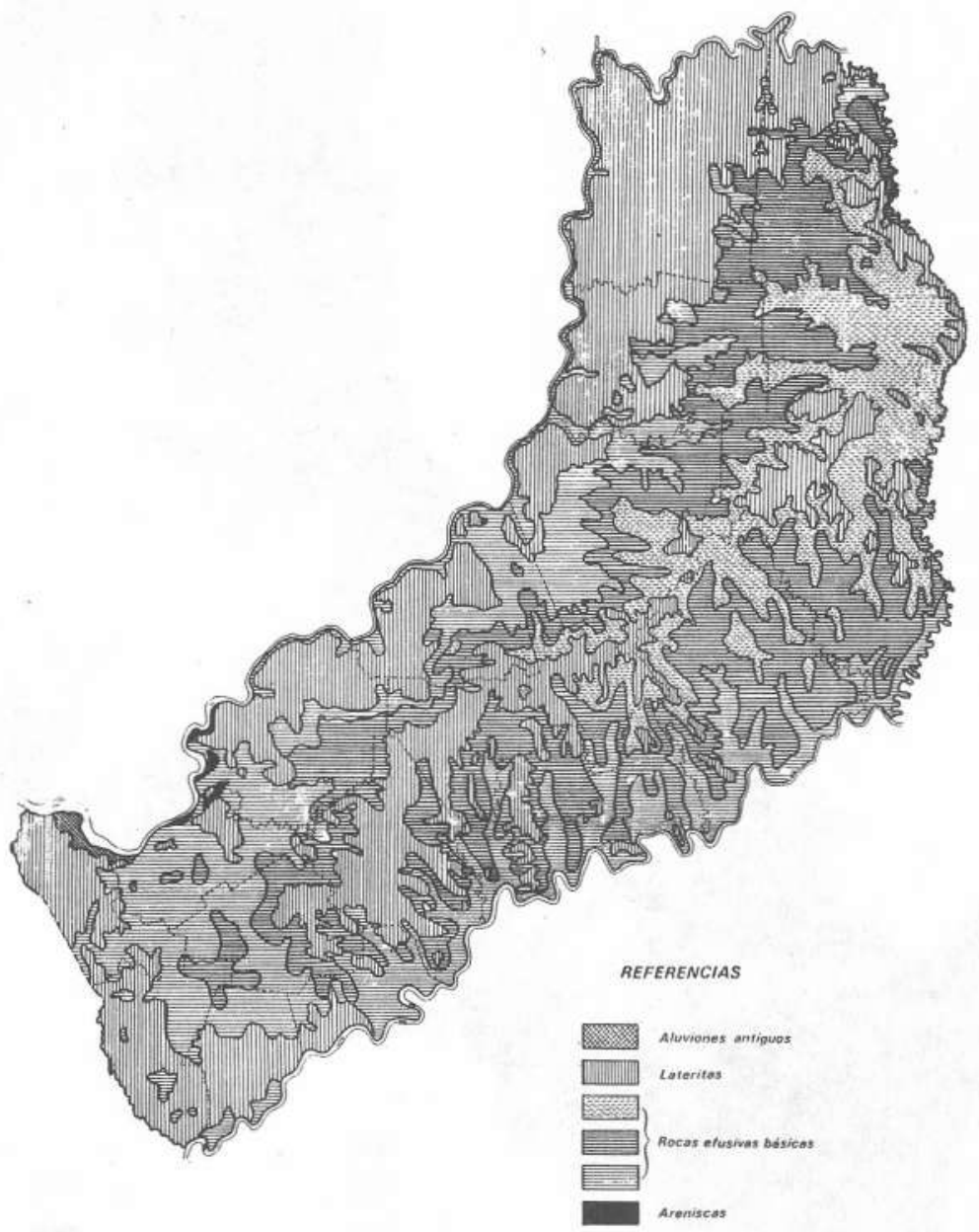

100

$50 \mathrm{Km}$

ESCALA 


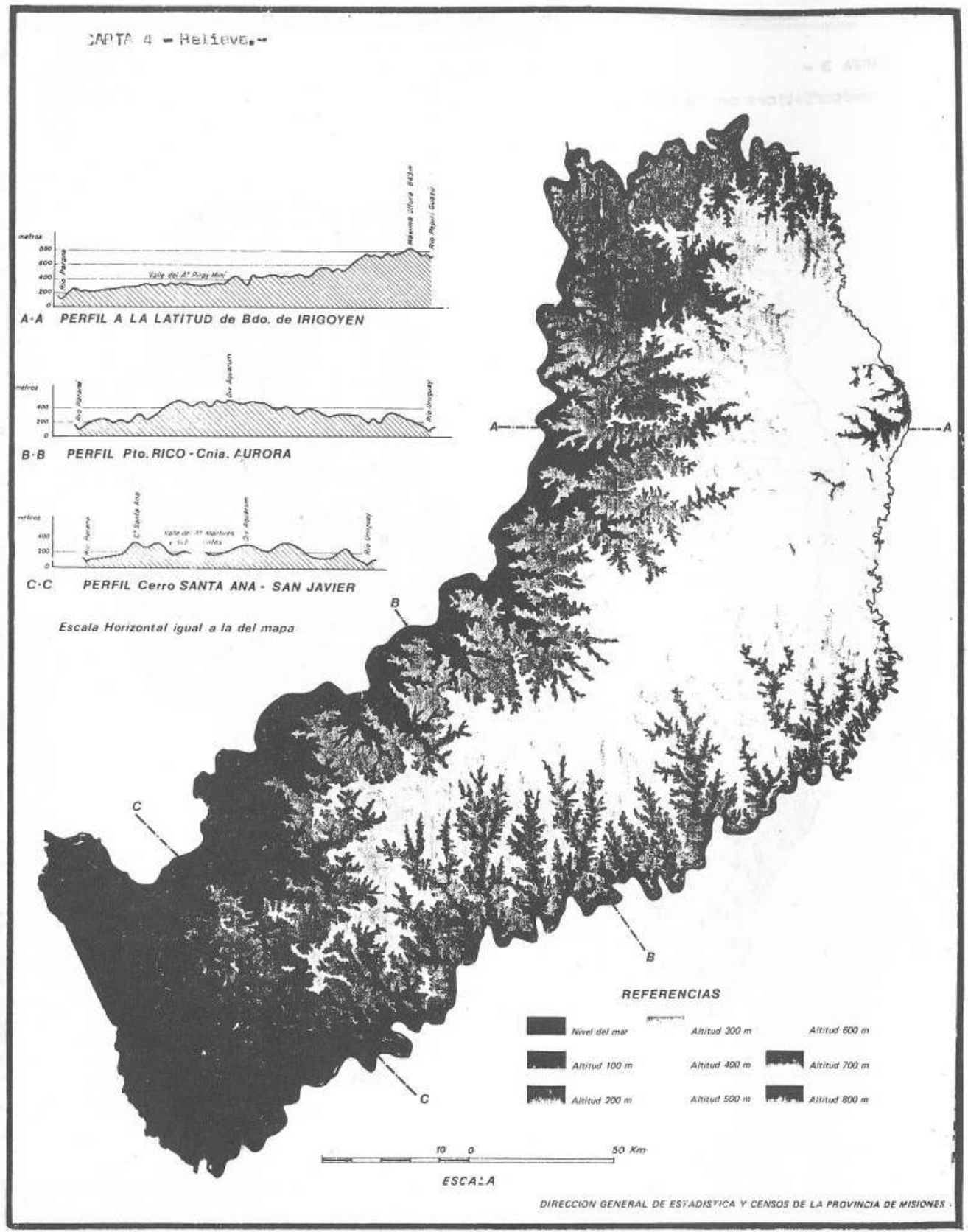


GARTA 5 -

Prealpiteciones y tomeareturase-

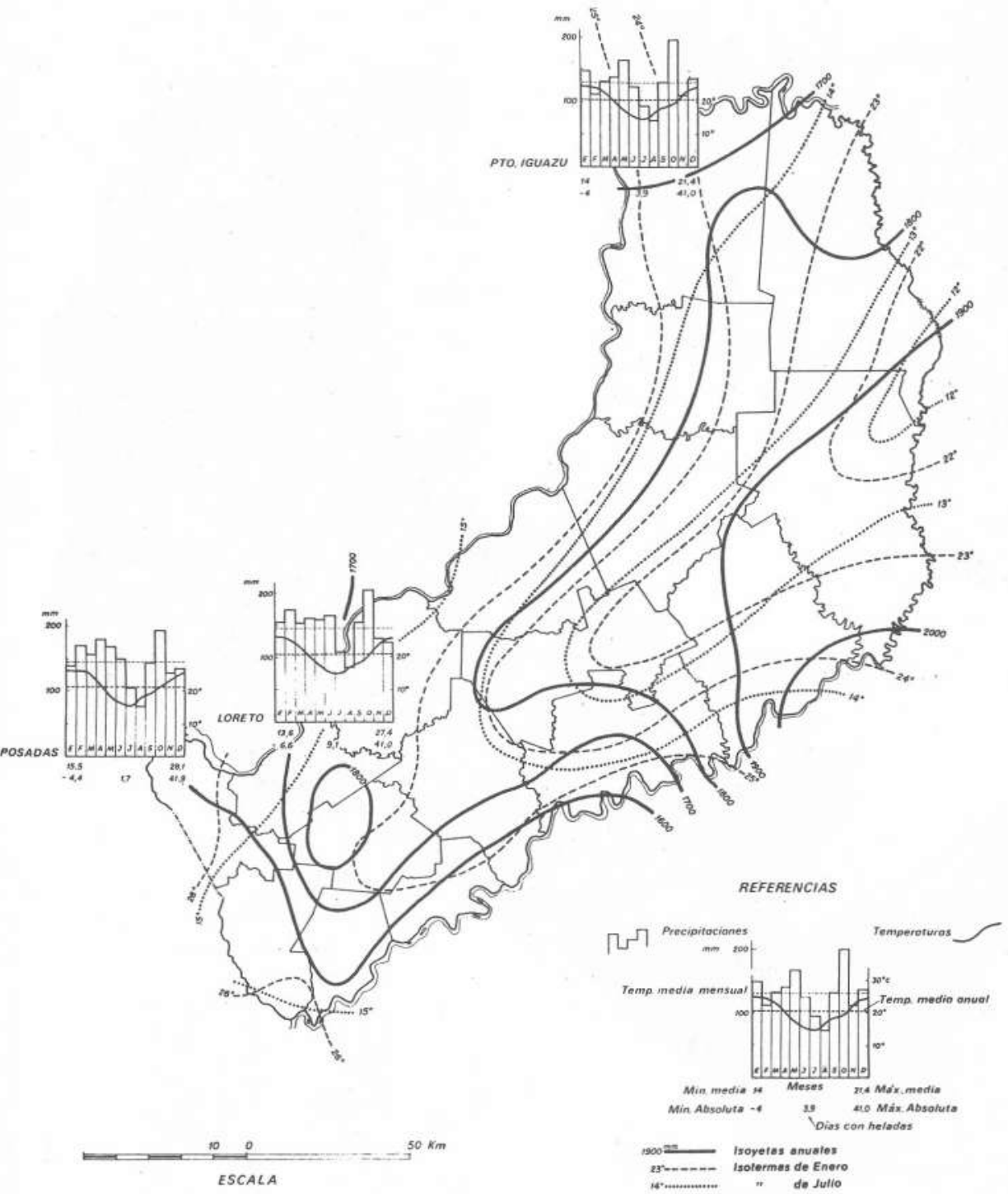


QNaTh 6 -

cursos de eque cubnges y jubcuencas.-
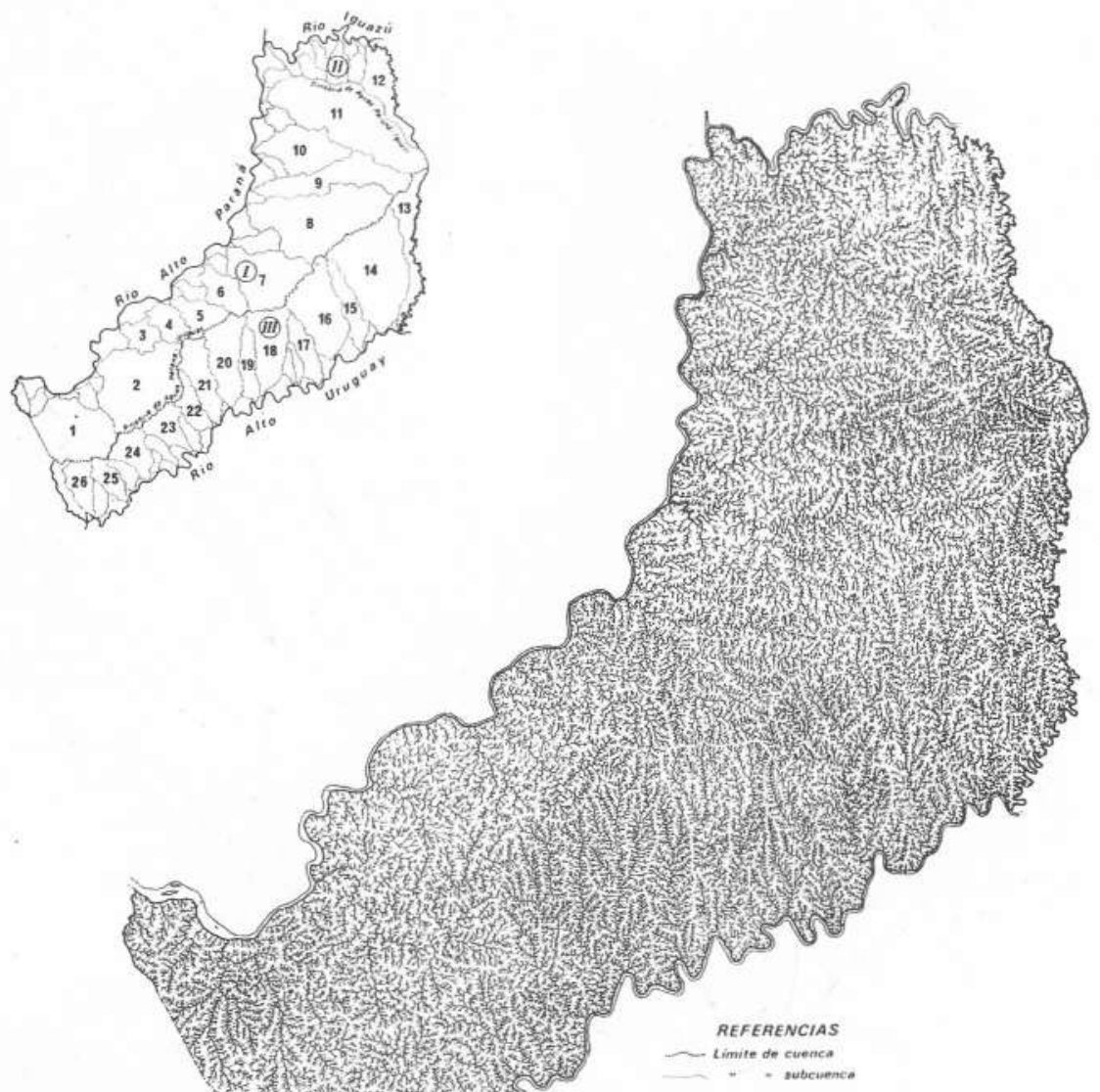

(I) Rio Parand (II) Rio Igvani

(iii) Aio Uruguary

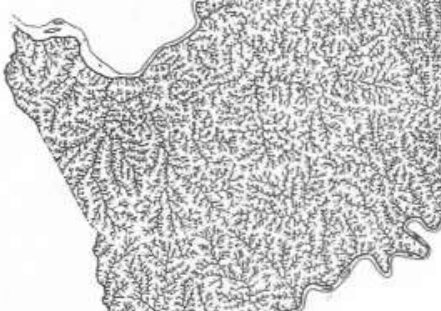

SUBCUENCAS

\begin{tabular}{|c|c|c|c|c|c|}
\hline 1 & Aeroyo & Garups & 14 & Arropo & o Pepiri Mini \\
\hline 2 & - & Vabebiry & 15 & - & Par $=$ iso \\
\hline 3 & . & Nacanguazú & 16 & - & Sobarbio \\
\hline 4 & - & Tabay & 17 & - & Chefariz \\
\hline 5 & - & Cunapurú & 18 & " & Soltito \\
\hline 6 & - & Garuhapd & 19 & 4 & Pindaiti \\
\hline 7 & . & Paranay Guatú & 20 & - & Canal Torto \\
\hline 8 & r & Piray Guazd & 21 & + & Acnrogus \\
\hline 9 & . & - Mini & 22 & " & Ramon \\
\hline 10 & * & Aguaray Guard & 23 & * & Toro \\
\hline 11 & " & Urugua-f & 24 & * & teacaruaró \\
\hline 12 & . & San Antowio & 25 & $n$ & Durnzao \\
\hline 13 & - & Pepiri Guazí & 26 & " & Las Tunas \\
\hline
\end{tabular}




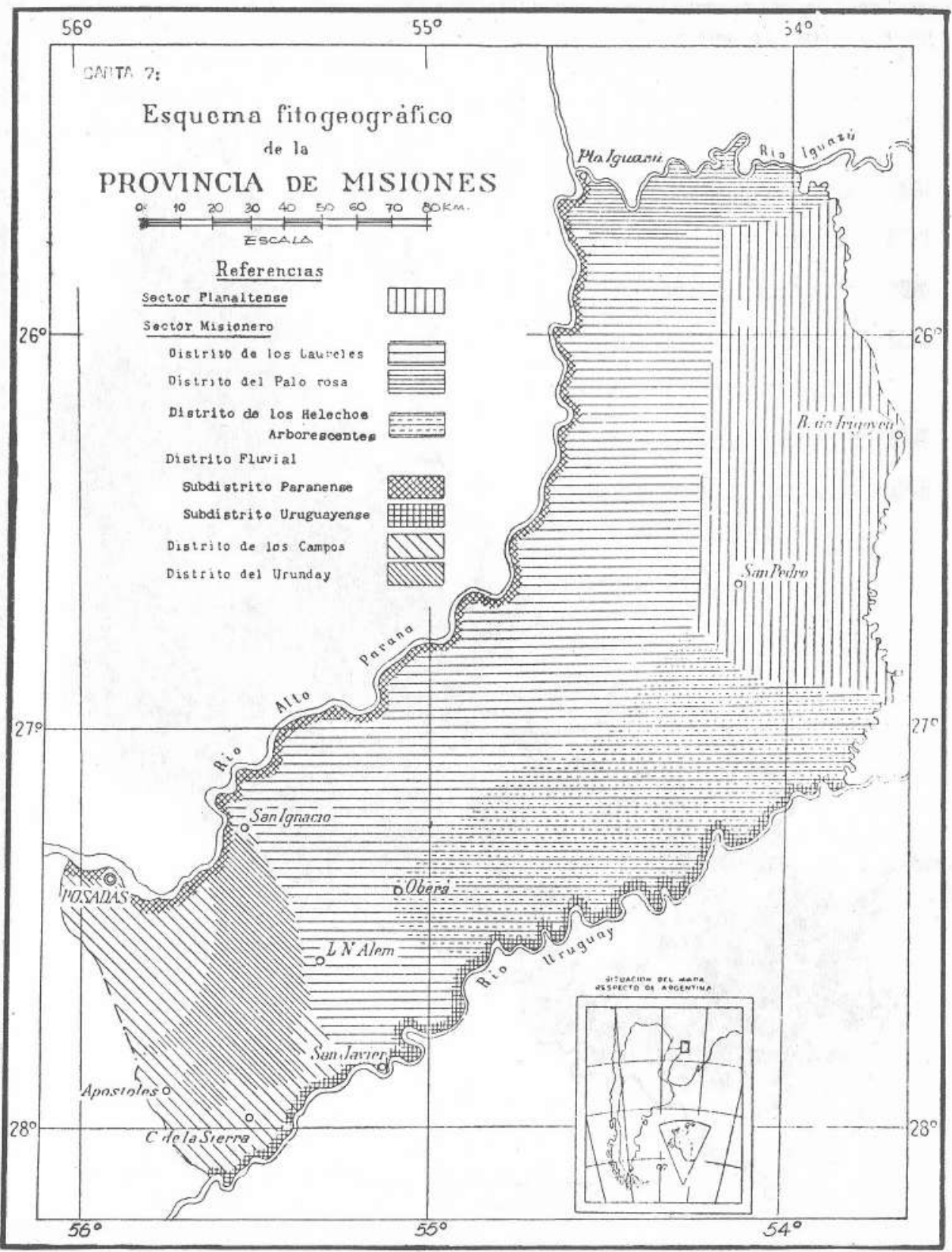




\section{REFERENCIAS}

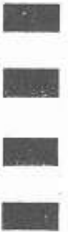

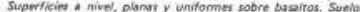

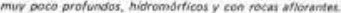

Suelos pedreyosce, sobre base tuadrica, cad plenos covil pendien-

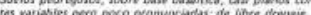

Suretus pedtegaess o inclinadoi, nobre buse bussiticas de libre

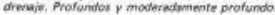

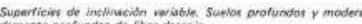

Superficies andialadas sobre dosaltos. Sumbas muy profundas de hibre drass:

Aress sobre basefios, con peoiertas andulaciones. Suelos profun. dos y moy grafundas de nibre drentaje.

Terrazas de erosido sobre basatro, tumazw afivionales a depow.

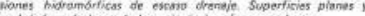

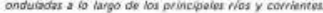

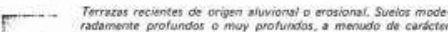
radamente profundos o muy arofundas, a menudo de cardeter

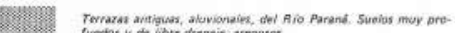
fundos $y$ de itibe drecuie; arevoses.
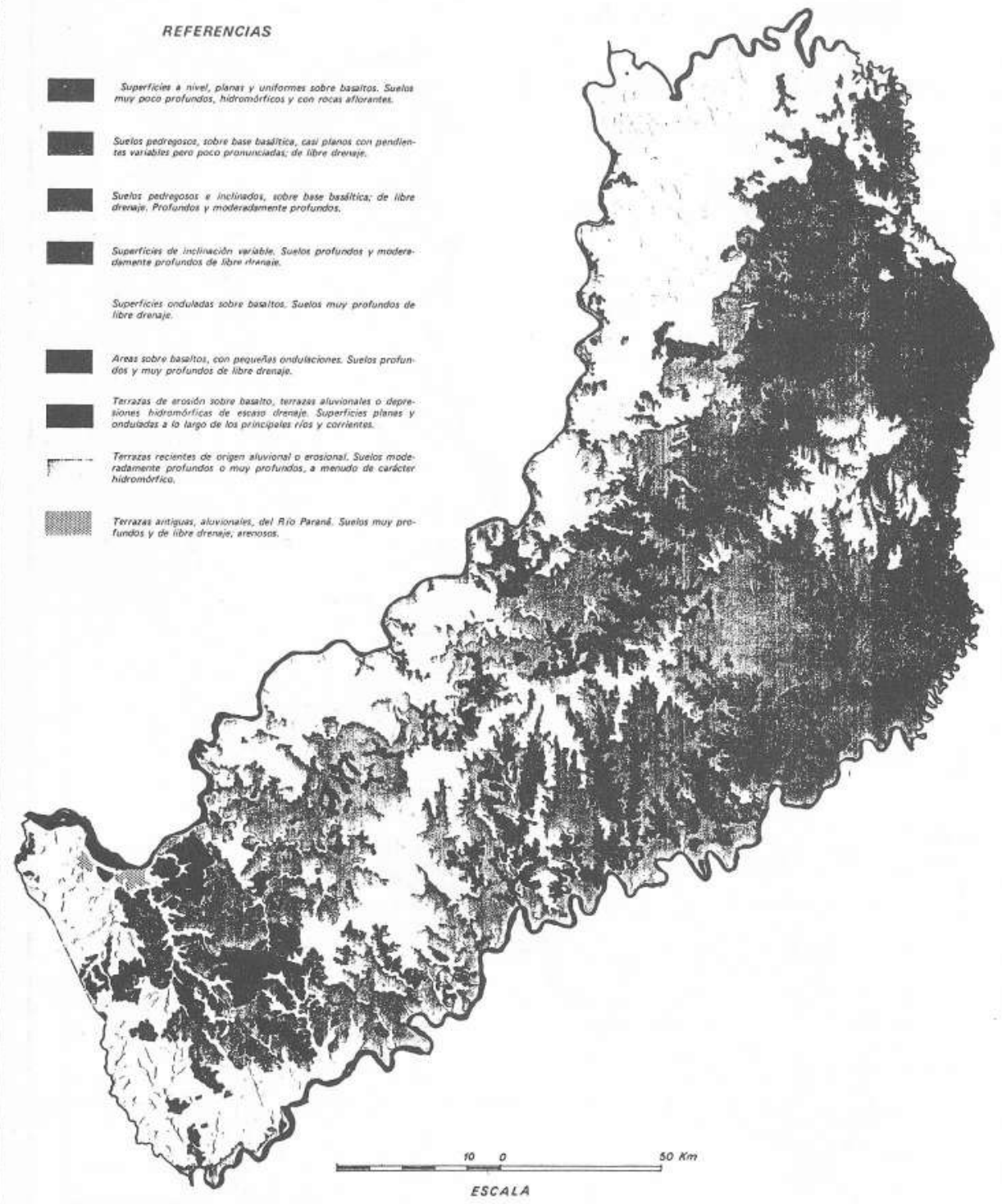

DIAECCION GENEAAL DE ESTADISTICA $Y$ CENSOS DE LA PAOVINCIA DE MISIUNE 
CAATA 9 , SITIOS INOIGENAS CCN OCUPACIONES LITICAS

APuTredicion HUIAT TA AL TOPARANANENSE

MITIONES; Dcupactonas 18-

$U=$ Tradic1ondisU -

3e INDUSTRIAS 3 de :MY:.-

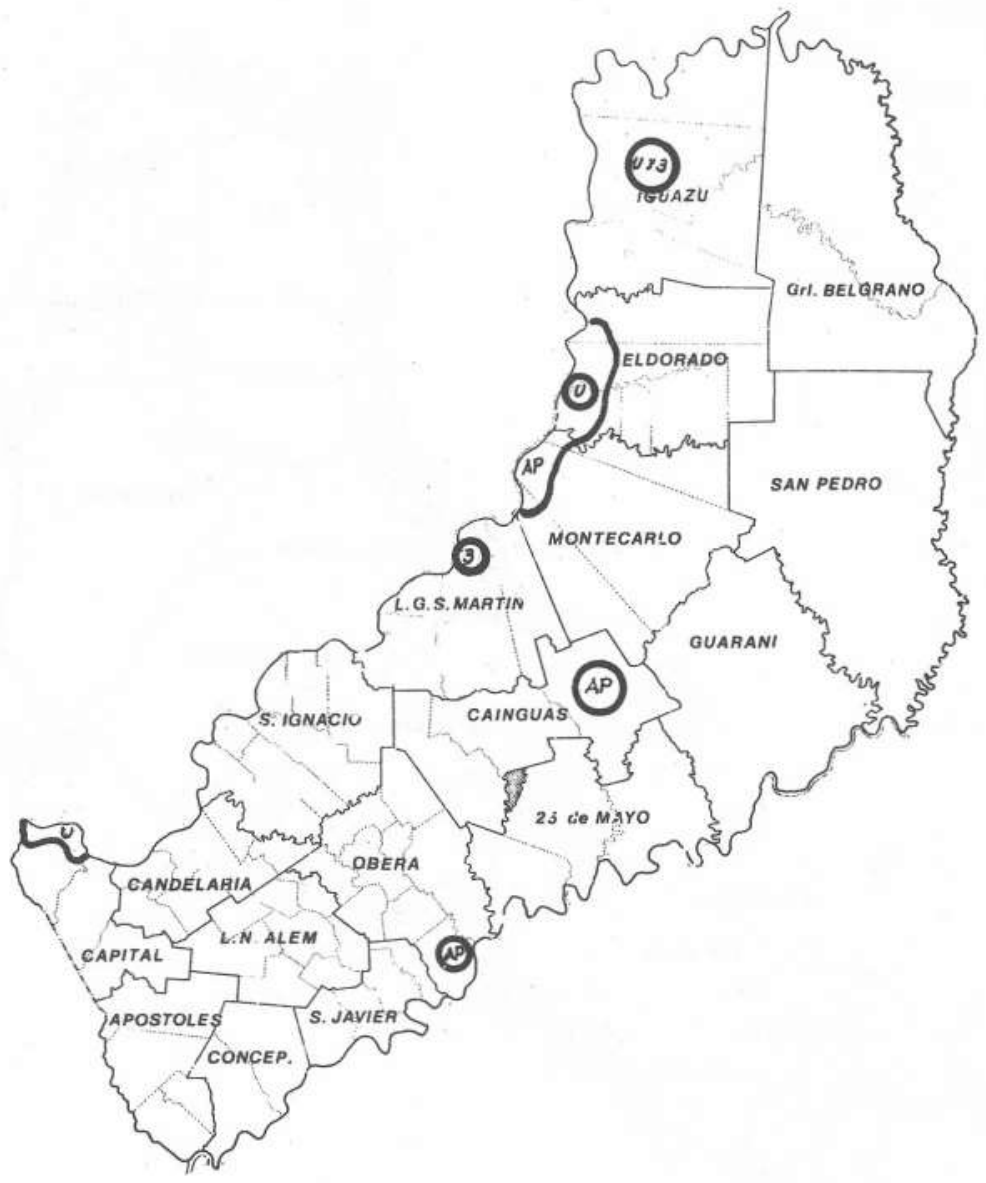

100 
CARTA 10; SITIOS INDIGENAS CON OCUPACIONES

LI TK-CERANTCAS.-

O-taguara - Eldormese

-TUPICUASAMI -

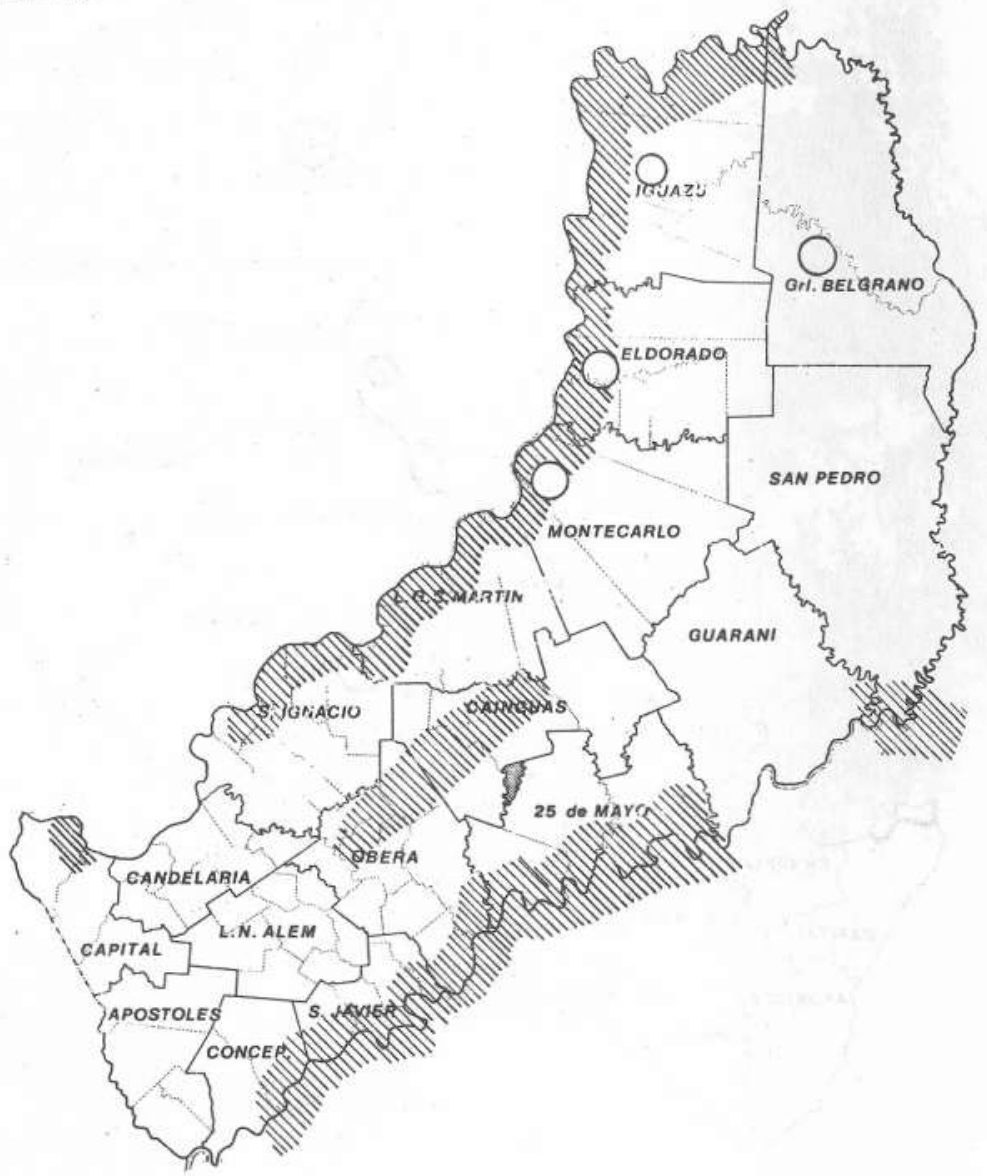




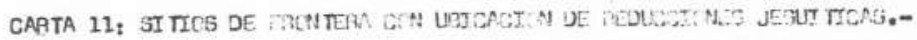
BEFEREIEIAS:

S/PRAANF: Itmpur: 25. F (16ts)

in 2n. F (1 rature Tuss)

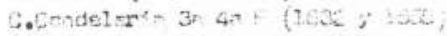

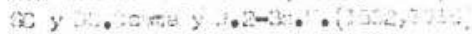

30 Bint $2-2-\cdot(2531 y+25)$

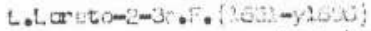

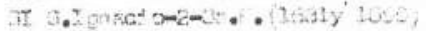

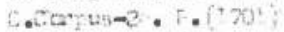

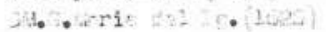

Thenger:

...

5.........

C. Tonutas it..t.

thooran.

1. R. P:

Z. Anth-

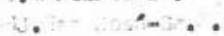

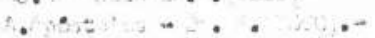

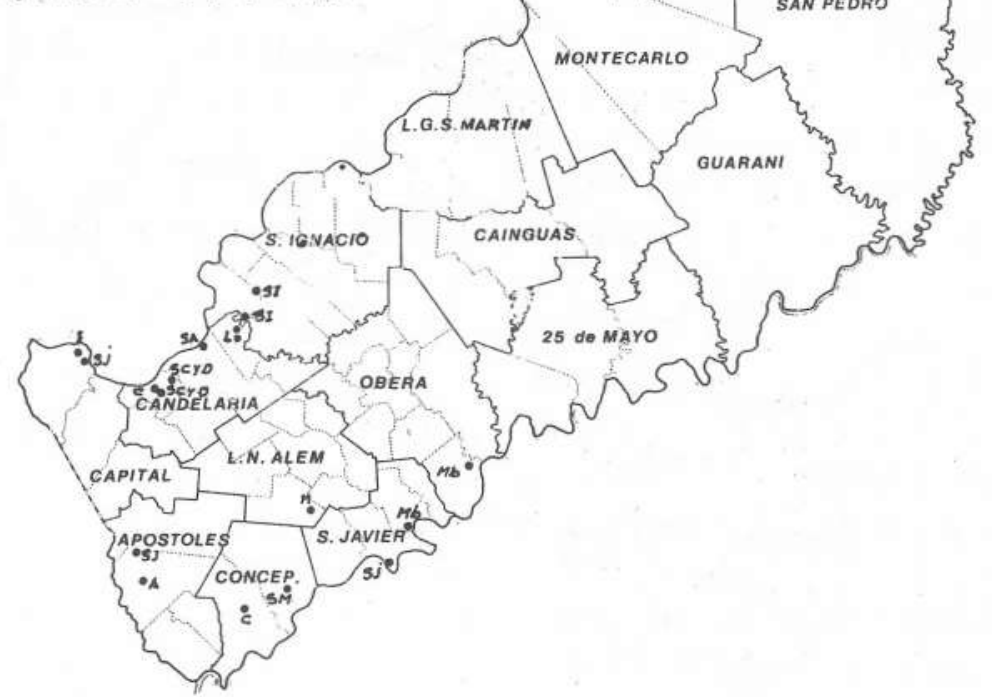

so $0 \quad 50 \mathrm{~km}$ 


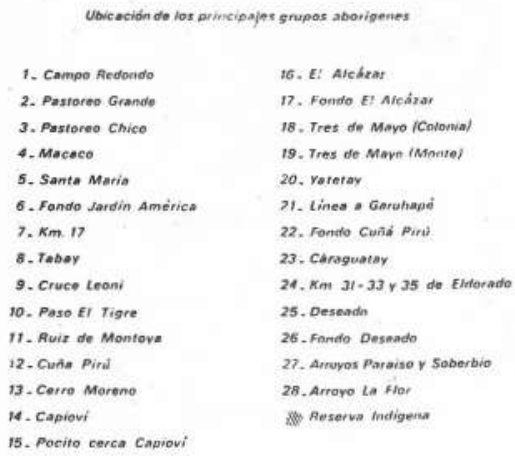

1. Campo Aedoerido

2. Pastoreo Grande

3. Pastorea Chico

4. Macace

5. Santa Maria

6. Fondo Jardin América

7. $\mathrm{Km}, \mathrm{n}$

s. Tabay

9. Cruce Leoni

10. Paso EI Tigre

11. Auiz de Montova

12. Cuna Piral

13. Cerro Mareno

14. Capioví

15. Pocito cerca Caprovi

16. E! Alebrat

17. Fondo El Afeázar

18. Tres de Mayo (Cotomia)

19. Tres de Mavn (Morate)

20. Yaretay

1. Linea a Garuhaped

22. Fondo Cuñă Parth

23. Caraguacay

24, Km $31-33$ y 35 de Ellorado

25. Deseadn

26. Fando Deseado

27. Arruyos Paraiso y Soberbio

28. Arrayo La flor

Xeserva Andigena
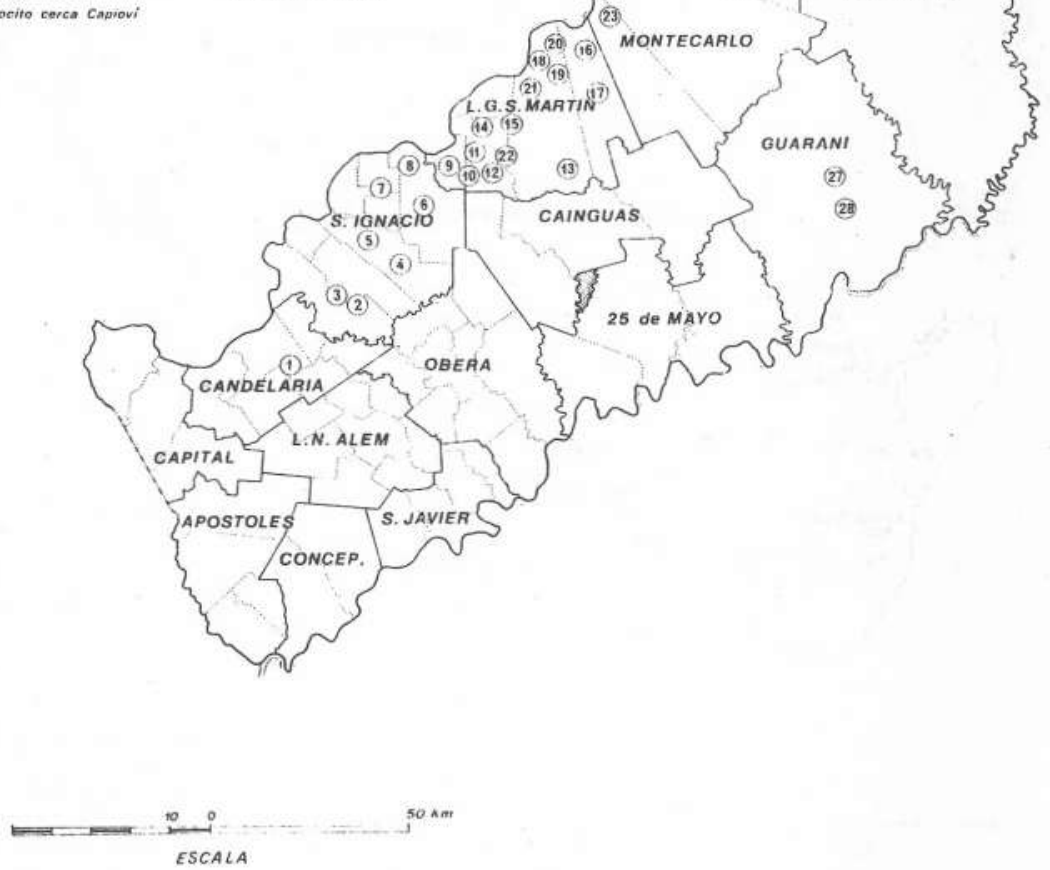